\title{
The Application of Microwave Heating in Bioenergy: A Review on the Microwave Pre- treatment and Upgrading Technologies for Biomass
}

\author{
Emily T. Kostas ${ }^{1 \S}$, Daniel Beneroso ${ }^{1}$, John P. Robinson ${ }^{1}$
}

${ }^{1}$ Microwave Process Engineering Research Group, Faculty of Engineering, The University of Nottingham, Nottingham, NG7 2RD, U.K.

TITLE RUNNING HEAD: A review on the microwave pre-treatment and upgrading technologies for biomass

$\S$ Corresponding author

e-mail: emily.kostas@ nottingham.ac.uk

Tel: +44 (0)1159514080 


\begin{abstract}
Bioenergy, derived from biomass and/or biological (or biomass-derived) waste residues, has been acknowledged as a sustainable and clean burning source of renewable energy with the potential to reduce our reliance on fossil fuels (such as oil and natural gas). However, many bioenergy processes require some form of pre-treatment and/or upgrading procedure for biomass to generate a modified residue with more suitable properties and render it more compatible with the specific energy conversion route chosen. Many of these pre-treatments (or upgrading procedures) involve some form of substantive heating of the biomass to achieve this modification. Microwave (MW) heating has attracted much attention in recent years due to the advantages associated with dielectric heating effects. These advantages include rapid and efficient heating in a controlled environment, increasing processing rates and substantially shortening reaction times by up to $80 \%$. However, despite this interest, the growth of industrial MW heating applications for bioenergy production has been hindered by a lack of understanding of the fundamentals of the MW heating mechanism when applied to biomass and waste residues. This article presents a review of the current scientific literature associated with the application of microwave heating for both the pre-treatment and upgrading of various biomass feedstocks across different bioenergy conversion pathways including thermal and biochemical processes. The fundamentals behind microwave heating will be explained, as well as discussion of the imperative areas which require further research and development to bridge the gap between fundamental science in the laboratory and the successful application of this technology at a commercial scale.
\end{abstract}

KEYWORDS: Biomass, Pre-treatment, Upgrading, Microwave heating, Bioenergy 


\section{$\underline{\text { Outline }}$}

1. Introduction

2. Microwave heating - the fundamentals

3. Application of microwave heating to pre-treat biomass

3.1 Thermal processing

3.1.1 The effects of MW-drying on biomass

3.1.2 MW-induced dry-torrefaction of biomass

3.1.3 MW-induced wet-torrefaction of biomass

3.1.4 MW-assisted organosolv pre-treatment

3.2 Bio-chemical processing

3.2.1 MW pre-treatment for bioethanol production via fermentation

3.2.2 MW pre-treatment for biogas production via anaerobic digestion

4. Opportunities, future directions and recommendations for MW research

4.1 Dielectric properties of biomass

4.2 Microwave apparatus and the importance of cavity design

4.3 Temperature control and monitoring

4.4 Understanding selective heating behaviour

5. Conclusions

6. Acknowledgements

7. References 


\section{Nomenclature and Abbreviations}

$P d \quad$ Power density $\left[\mathrm{W} / \mathrm{m}^{3}\right]$

$f \quad$ Frequency $\quad\left[\mathrm{s}^{-1}\right]$

$\varepsilon_{0} \quad$ Permitivity of free space $[\mathrm{F} / \mathrm{m}]$

$\varepsilon \quad$ Dielectric constant

$\varepsilon " \quad$ Dielectric loss factor

E Electric field magnitude $[\mathrm{V} / \mathrm{m}]$

$\tan \delta \quad$ Loss tangent

MW Microwave

DT Dry torrefaction

WT Wet torrefaction

HHV Higher Heating Value

AD Anaerobic digestion

EPS Extracellular Polymeric substance

WAS Waste activate sludge

SCOD Soluble chemical oxygen demand

TCOD Total chemical oxygen demand

TS Total Solids

AOP Advanced oxidation process

$\bullet$ OH Hydroxyl radicals

HRAP High rate algal ponds

HRT Hydraulic retention time

TEA Techno-economic analysis

LCA Life cycle analysis

IU Units of enzyme activity 


\section{Introduction}

Biomass has the potential to become a major global energy source, with the ability to make a substantial contribution to the sustainable future energy demand [1]. Biomass resources can be considered as organic matter in which solar energy is stored in the chemical bonds of the molecules within the feedstock. When these bonds between adjacent carbon, hydrogen and oxygen atoms are broken this stored, chemical energy is released [2]. Furthermore, energy carrier sources, otherwise known as 'biofuels', that can be produced from such bio-based materials have the potential to reduce atmospheric $\mathrm{CO}_{2}$ emissions. This is due to a balance in net $\mathrm{CO}_{2}$, since the $\mathrm{CO}_{2}$ which is released from the burning of the biofuel is proportional to the $\mathrm{CO}_{2}$ that was fixed from the atmosphere by the plant during photosynthetic biosynthesis [3]. At present, biomass is the largest contributor towards renewable energy, as forestry, agricultural and municipal residues and waste have all been used as the principal feedstocks for the production of electricity and heat [4]. Within the European Union, biomass accounts for more than $62 \%$ of all renewables, with wood accounting for approximately $80 \%$ of the biomass used for renewable energy [5, 6]. In the transport sector, biofuels are already widely deployed in several countries and are being produced on a commercial scale. This is mainly $1^{\text {st }}$ generation bioethanol from corn and sugar cane in Brazil and $2^{\text {nd }}$ generation bioethanol from straw and corn stover in the US [7].

There are a number of different bioenergy routes (processes) that can be applied to convert raw biomass feedstocks into final energy and chemical products which are typically divided into two main categories: thermochemical and biochemical conversion routes. Figure 1 illustrates the main bioenergy conversion routes that have already been successfully employed or are currently the subject of further research and development for the production of renewable fuels. Other routes may require the inclusion of a biomass pre-treatment step 
(such as applied thermochemical pre-treatment prior to enzymatic saccharification in the case of bioethanol production) or biomass upgrading [8]. Each different route typically consists of a series of conversion steps that transform the raw biomass feedstock into an energy carrier such as heat, electricity or liquid or gas-based biofuel [1]. The preferred bioenergy conversion route often depends on many factors such as specific feedstock type and the quantity available, the desired form of the energy product, the current availability of the processing technology, environmental standards and the economic conditions [1, 2]. However in most cases, it is ultimately the form in which the energy is required that is the main governing factor, followed by the availability and quantity of biomass feedstocks [2].

Although biomass has the potential to produce both cleaner-burning and also more sustainable sources of fuels compared to fossil fuels, there are disadvantages associated with the use of biomass feedstocks. For example, their lower energy densities and heterogeneity in physical nature make handling, transport and storage more complex and more expensive than fossil fuels [9]. Furthermore, there is a high degree of variation in the chemical composition, moisture and alkali contents across different biomass feedstocks. This requires some form of pre-treatment in order to meet the requirements for quality and homogeneity for the successful application of many conversion technologies [1]. Biomass upgrading and/or pretreatment protocols are therefore key steps required for the efficient conversion of biomass into energy products and can significantly affect both the efficiency and choice of methodology of the subsequent energy process [10]. The primary goal of pre-treatment is to overcome the recalcitrant nature of the feedstock [11] and to modify its structure; making the feedstock more amenable for conversion into a final product. Pre-treatments also serve a purpose of increasing the surface area and pore volumes $[12,13]$. However to include such a step in a biomass conversion process is relatively expensive and in the case of bioethanol production for example, pre-treatments may contribute to ca. $18 \%$ of the total production cost 
[14-17]. Nevertheless, enhancing the final product yield (e.g. biofuel yield) through improved and optimised pre-treatment applications could significantly reduce the costs of prior process units; hence the overall cost of the production process can be reduced by increasing the pretreatment efficiency [18]. Therefore, an ideal pre-treatment should be one that is suitably affordable with relatively low energy requirements, low resource consumption and limited waste streams to make the overall process environmentally friendly and sustainable. Above all, the pre-treatment and/or biomass upgrading process should aim to overcome the natural challenges imposed by notoriously recalcitrant and heterogeneous feedstock materials and generate a residue with a modified structure that may give it ideal properties that are more compatible with the chosen energy conversion route.

The development of microwave (MW) technology has gained an increasing amount of attention as an alternative non-conventional heating source that can be applied for the processing of biomass and wastes [19, 20]; particularly for the pre-treatment and biomass upgrading steps.

The purpose of this review article is to identify and discuss the latest scientific literature associated with the application of MW heating to pre-treat and upgrade biomass. This review is structured in two main parts. The first part focusses on the latest research developments which use MW-based heating as a means to upgrade and pre-treat different feedstocks. The application of dielectric heating across different conversion routes within the sustainable energy spectrum are collated and will be discussed to establish the advances MW heating has had across the various areas of bioenergy and biochemical production. Particular attention will be devoted to explain how MW pre-treatment/upgrading has overcome hurdles involved with each bioenergy route. The second part discusses the technological challenges that currently exist with the technology and the future areas of research that need to be addressed if this form of heating is to become widely industrially applied. This review will be of benefit 
to those who are not experts with the use of MW technology and the understanding of electric field theory, yet utilise MW based systems to pre-treat and upgrade biomass.

\section{Microwave heating - the fundamentals}

Microwaves (MW) are a form of electromagnetic energy located on the electromagnetic spectrum between 300 and 300,000 MHz; a region that lies between infrared and radio frequencies and correspond to wavelengths of $1 \mathrm{~cm}$ to $1 \mathrm{~m}[21,22]$. In order to avoid interference with telecommunications and mobile cellular phone frequencies, most microwave reactors (that are typically used for chemical synthesis reactions) and domestic microwave ovens operate at a frequency of $2.45 \mathrm{GHz}$ or around $900 \mathrm{MHz}$, whilst other frequencies are reserved by the Federal Communications Commission (FCC) for industrial, scientific and medical purposes [23, 24].

MW heating occurs due to two main mechanisms, which efficiently induce rapid heating when MWs are in contact with polar molecules or ions; dipole rotation and ionic conduction. Dipole rotations are interactions that occur as polar molecules attempt to realign themselves with the rapidly oscillating electric field of the MW $[25,26]$. During this phenomenon, energy is lost in the form of heat through molecular friction and dielectric loss [24] (Figure 2). When a MW-absorbing material is placed within an alternating electric field energy is irreversibly absorbed, which results in rapid 'volumetric' heating. Figure 2 illustrates this type of heating, as the centre of the block of wood has clearly been heated to a significantly higher temperature than the outer material. Essentially, MW heating is the reverse of conventional heating, where heat is transferred to the surface of a material (from an external heat source) by conduction/convection or radiation and is then transferred towards the cooler interior regions by thermal conduction. MW heating can therefore be described as a form of energy conversion rather than a form of heating; as electromagnetic energy is converted into 
heat [27]. This unique inverse heating profile mechanism offers many benefits such as an increase in energy transfer efficiency and reductions in process heating time (to achieve a given temperature). Unlike conventional heating methods, the heating effect is almost instantaneous; no time is spent waiting for the source to heat up or cool down [28]. Furthermore, it enables better control of the heating process itself and eliminates the risk of the sample surface overheating and possibly degrading (whilst the inner part has not yet been heated) and as such this could be a useful technique that could be applied for the drying of wet materials [29].

However, not all materials have the ability to absorb MWs. Materials can be generally categorised as either (1) MW-transparent/insulator (e.g. glass and ceramics) where the MWs pass through the material without any losses, (2) MW-conducting (e.g. metals) in which the MW do not penetrate and are instead reflected, or (3) MW-absorbing (e.g. polar molecules such as water) where the MWs are absorbed and converted into heat [27]. The relative extent of MW heating of any given material can be determined by a term called the 'loss tangent' $(\tan \delta)$ defined by the following equation:

$\tan \delta=\frac{\varepsilon^{\prime \prime}}{\varepsilon^{\prime}}$

where $\varepsilon^{\prime}$ is the dielectric constant of the material (the ability of the material to store electromagnetic energy) and $\varepsilon$ "' is the dielectric loss factor (the ability of the material to convert the stored electromagnetic energy to heat). In general, materials can be classified as high $(\tan \delta>0.5)$, medium $(0.1-0.5)$ and low microwave absorbing $(<0.1)$ [30]. Materials which exhibit a low $\tan \delta$ value are not necessarily exempt from being used in a MW heating system provided that high intensity electric fields are supported.

Many studies cite energy efficiency as an advantage of microwave heating, however the energy input required to heat a given quantity of biomass will be the same, regardless of 
whether MW or conventional heating methodologies are used [31-33]. The advantages of MW heating are related to selective and volumetric heating, rather than energy. Selective heating occurs when a feedstock is heterogeneous, and contains different materials or phases with different $\tan \delta$ values. Components with higher $\tan \delta$ values will attain higher temperatures than those with lower $\tan \delta$ values, leading to thermal gradients within the biomass that are unique to MW heating and have the potential to alter the decomposition pathway and subsequent product chemistry. Selective heating also allows biomass to be heated directly within a cold environment, without the need for hot gases or ablative surfaces. Volumetric heating allows conventional heat transfer limitations to be overcome, resulting in much higher heating rates, smaller processing equipment and the ability to process large particle sizes $[27,33]$. The overall process system can benefit from volumetric heating as the overall flowsheet can be significantly simplified, with reduced requirements for feedstock size reduction, hot gas handling and recovery systems and the overall size of the equipment. Whilst the energy requirements are comparable with conventional processes, MW heating offers opportunities to reduce the capital cost of the processing system and the ability to produce products that are unobtainable with conventional systems.

\section{Applications of microwave heating to pre-treat biomass}

A number of alternative pre-treatment technologies are currently being applied for the intensification of biomass and waste, which include ultrasound assisted processing [34-37], steam explosion [38-40], ammonia fiber explosion (AFEX) [41-43], and extrusion [44-46]. However MW technology represents an alternative and reliable option to conventional thermal and/or sonochemical pre-treatment systems, and has applications across many different energy conversion routes. It enables the use of an alternative type of chemistry (which is specifically unique due to its internal heating phenomenon) and thus guarantees 
heating rates that rapidly achieve the target reaction temperature [47-49]. In this section, a selection of different thermal and biochemical processing routes which have applied the use of MWs to both upgrade and pre-treat biomass are discussed and the latest literature is evaluated, with specific reference to the effects of MW treatment on the biomass.

\subsection{Thermal processing}

\subsubsection{The effects of MW-drying on biomass}

Drying is usually a necessary pre-requisite prior to biomass processing [50], however it is one of the most energy-intensive unit operations in post harvesting processing of biomass [51]. The primary aim of reducing the water content of biomass is 1) improve the energy efficiency of further biomass processing, 2) improve product quality and 3) prolong the shelflife of products (which may be produced via different bioenergy conversion routes). This is achieved by reducing the water content to a level low enough to prevent the growth of microorganisms, reduce enzymatic reactions and any other deteriorative reactions [51]. This is certainly the case for pyrolytic derived bio-oil, as phase separation will occur if the water content of the bio-oil is over $30 \%$ [52]. Furthermore, the calorific value and the quality of the fuel ultimately produced will decrease if water is present [53]. In order to reduce the probabilities of this from occurring, reducing the moisture content is a crucial pre-treatment step for biomass processing. A moisture content of ca. $10 \%$ is the ideal target required prior to processing $[54,55]$, however the drying process of biomass feedstocks, if performed using conventional heating, can consume up to $60 \%$ of the total energy that is required to produce the biofuel itself [56]. In contrast MWs are capable of drying biomass at a higher rate with a more effective distribution of heat than conventional hot air drying [57-59]. Interestingly, research has shown that the MW-based drying of biomass can improve pore structure, which ultimately optimises the combustion properties of the raw material $[60,61]$. 
A study by Wang et al [54] investigated the effects of MW drying on three different biomass wastes (pine wood sawdust, peanut shell and maize stalk) prior to pyrolysis. The study analysed the influence of MW drying (at four different power levels - 200, 400, 600 and 800 W) on the subsequent behaviour of biomass pyrolysis, compared to pyrolysis after conventional drying. The first noticeable difference was the fast drying rate and removal of water from the feedstocks; 6 min at $600 \mathrm{~W}$ in a MW oven compared to $40 \mathrm{~min}$ at $105^{\circ} \mathrm{C}$ in a conventional oven. When samples of biomass dried at $600 \mathrm{~W}$ for 6 min were selected for pyrolysis, it was noticed that the yields of bio-oil and char increased while the yield of gas decreased. The authors suggested that this observation may be attributed to a decrease in secondary reactions of volatile compounds produced, thus resulting in increased bio-oil and char fractions. MW drying was also shown to improve the combustion performance of food waste by up to $35 \%$ compared to electrically dried samples, as a study by Liu et al [62] demonstrated that MW drying at $1500 \mathrm{~W}$ accelerated the combustion kinetics by reducing the ignition temperature and increasing the activation energy at high temperatures. The MW drying characteristics of the highly abundant and lipid rich microalga Chlorella vulgaris were analysed for its suitability for biofuel production [55]. The study revealed that MW drying of the microalga at a power intensity of $20 \mathrm{~W}$ per $\mathrm{g}$ (of algae) was ideal for biofuel production as this setting gave a lower specific energy requirement and produced a dried residue that still retained a high lipid content; therefore rendering it an ideal feedstock for biodiesel production. It can therefore be concluded that MW-based drying of biomass is highly effective before its subsequent conversion to a final product of energy, (regardless of the actual method for conversion used). Despite the reported MW energy consumption being higher than conventional oven drying, the significantly shorter processing time and enhanced quality of targeted products can offset the extra energy required. 


\subsubsection{MW-induced dry-torrefaction of biomass}

Dry torrefaction (DT) is a biomass pre-treatment process that is considered to be the least severe form of thermochemical processing. DT is a low temperature process $\left(200-300^{\circ} \mathrm{C}\right)$ that takes place in the absence of oxygen for a duration of ca. $1 \mathrm{~h}$ or less [63]. The process yields a solid product that has improved combustible properties with an increased energy density than the original untreated biomass $[64,65]$. DT induces changes in the biomass due to the thermal decomposition of hemicellulose and the partial depolymerisation of lignin and cellulose, which as a result produces a torrified biomass with a higher carbon content, but a lower overall mass and a higher calorific value [66]. Additionally, torrified biomass is hydrophobic, resistant to biological decomposition, has improved grindability and when pulverised and displays more uniform and smaller particle sizes [67]; properties which are better fuel characteristics for combustion and gasification purposes and exhibit similar characteristics to coal [65]. Most of the studies on the DT of biomass have used conventional heating methods as the heating source, and the effects of various processing temperatures and times have been investigated [68-70]. However in the last few years, MW induced DT of biomass has become a growing area of research. Table 1 summarises the different biomass feedstocks which have been torrified by means of microwave heating. These include corn stover [71, 72], rice straw and pennisetum [73], along with the treatment conditions and the characteristics of the torrified biomass product. The majority of the studies listed in Table 1 investigated the effects of different experimental conditions including microwave power, processing time, biomass water content as well as particle size on the characteristics of torrified biomass. The key findings from most of these studies revealed that microwave power and reaction time were the primary factors which affected the torrefaction process, whereas the moisture content of the biomass did not have a significant effect [73-76]. Due to the fact that water is a good susceptor of MW heating [77], biomass can be directly torrified 
without the requirement of a pre-drying step. Compared with conventional heating methods, comparable mass and energy yields can be achieved by microwave heating at lower power levels and shorter reactions times; implying that the energy input of microwave torrefaction is lower [73]. MW induced dry-torrefaction also significantly improved fuel characteristics such as the Hydrogen/Carbon and Oxygen/Carbon ratio, Higher Heating Value (HHV; indicative of calorific value) and the energy density of the torrified samples [76]. Furthermore, the grindability and hydrophobicity of the torrified biomass is greatly improved by MW torrefaction [74], which may be attributed to the unique selective heating mechanism of MWs. However in the work conducted by Satpathy et al [74], it was noticed that MW heating at low power and short reaction times unevenly heated the biomass and produced a torrified biomass containing 'hot spots'. This phenomenon is typically seen as a result of MW heating, due to the non-homogenous nature of the biomass sample in conjunction with the selective heating mechanism of MWs and the uneven distribution of the electric field as a consequence of the use of non-optimised MW ovens. In order for the MW-torrefaction of biomass to become a competitive technology that generates torrified biomass efficiently, bottlenecks associated with MW heating (such as the aforementioned heating hot spots) need to be addressed and overcome through electromagnetic design of the torrefaction reactors. These issues are addressed and discussed later in this review article.

\subsubsection{MW-induced wet-torrefaction of biomass}

Wet torrefaction (WT), additionally known as hydrothermal pre-treatment, refers to the heating of a suspension of biomass and subcritical water at $180-250^{\circ} \mathrm{C}$ under a self-generated saturation pressure, typically with reaction times between $30 \mathrm{~min}$ and several hours [78-80]. The process, which is exothermic, generates three main products: gases, aqueous chemicals and a solid residue (hydrochar) [81] which is the main product of WT accounting for up to $88 \%$ of the mass and almost $90 \%$ of the energy in the raw biomass [82]. The mechanisms 
involved in the WT of biomass generally differ to the mechanism of the DT variant. DT includes the following reactions: decarboxylation, dehydration, de-carbonisation, demethoxylation, intermolecular rearrangement, condensation and aromatization chemical reactions [83]. In contrast, due to the presence of compressed water in WT, a hydrolysis process mechanism is followed which cleaves the ester and ether bonds between molecules and in so doing, the activation energies for the depolymerisation reactions of the biomass polymers decrease [84]. Consequently, the degradation of hemicellulose during WT is higher than that in the DT process. The WT process is considered to be less toxic and more environmentally friendly compared to DT, as the only input streams are the biomass itself, water and an inert gas. In addition the fuel properties, including the energy density and the HHV of the torrified product are superior to those obtained with DT [85]. The application of biomass WT has gained popularity due to its suitability for upgrading biomass and/or biomass wastes which contain relatively high amounts of moisture (typically above 50\% [wet basis]) [86]. Just like DT, WT does not require a pre-drying of the raw biomass; making this form of pre-treatment economically attractive. This implies that a wider range of biomass feedstocks (including aquatic based biomass for example) may be suitable for WT pretreatment and ultimately the solid fuels produced have increased calorific value, improved grindability and pelletability, and a lower ash content [78].

Published research using MW-assisted heating for WT of biomass is scarce and only a small number of studies can be found in the scientific literature. However, increased numbers of research groups have started to evaluate the potential of using MW-WT on a number of different biomass feedstocks with subsequent evaluation of the energy properties of generated hydrochars. Chen et al [87] used MWs to torrify sugarcane bagasse and found that the energy density and heating value of the torrified feedstock had improved by $20.3 \%$ compared to DT. A study by Elaigwu and Greenway [88] compared the energy yields of hydrochars prepared 
by MW-WT of rapeseed husks. The subsequent hydrochars produced were generated by heating the biomass in deionised water in a MW oven at temperatures of $150-200^{\circ} \mathrm{C}$ for a specific period of time. The study found that higher reaction temperatures and longer residence times had led to an increase in the heating value of the hydrochars by approximately $32 \%$ at $200^{\circ} \mathrm{C}$ and by $25 \%$ for $30 \mathrm{~min}$. In a separate study, bamboo was subjected to MW-WT in dilute hydrochloric acid solutions and water at $180^{\circ} \mathrm{C}$ for $5-30 \mathrm{~min}$ [81]. The group found that after MW-WT using $0.2 \mathrm{M} \mathrm{HCl}$ for $20 \mathrm{~min}$ the higher heating value (HHV) of the hydrochar $\left(24.86 \mathrm{MJ} \mathrm{kg}^{-1}\right)$ was higher than Converse School-Sub coal (21.67 $\mathrm{MJ} \mathrm{kg}^{-1}$ ) and comparable with German Braunkohole lignite (25.10 $\mathrm{MJ} \mathrm{kg}^{-1}$ ). This study revealed the potential of producing hydrochars via MW-WT with either similar or even higher HHV than examples of coals already used in industry. For the first time, the effects of MW-WT on the heating values and fuel properties of hydrochar produced from a microalgal species (in this case from Chlorella vulgaris ESP-31), were investigated in the work of Bach et al [89]. The calorific value of the microalga was intensified by up to $21 \%$ and also up to $61.5 \%$ of the energy in the alga was retained after MW-WT. A further finding from this work was the significant reduction in the content of ash between the initial microalgae biomass and the generated hydrochar. This highlights the potential of using MW-WT as an effective method to pre-treat biomass feedstocks with high ash contents, and reduces the possibilities of ash related problems associated with microalgal utilisation for solid fuels. Macroalgae (seaweeds) are another feedstock that are high in ash, with some species such as Palmaria palmata having an ash content as high as $25.7 \%$ [dry weight basis; $\mathrm{d} / \mathrm{w}$ ] [90]. These contents are substantially higher than the amounts present in most terrestrial plants in their native (non-pre-treated) form, as seaweeds have the ability to easily absorb inorganic substances from their environment [91]. At the time of writing, only one paper had been published which evaluated the HHV of brown seaweed Ascophyllum nodosum residue that was recovered after 
MW- assisted acid hydrolysis [92]. Although this work is traditionally classified as WT, it did however demonstrate that MW heating of seaweed with an additional acid catalyst can efficiently produce a liquid product stream rich in sugars and also a hydrochar residue with an energy yield of more than $50 \%$ in one process. Furthermore, optimal pre-treatment parameters generated a hydrochar that had a $\mathrm{HHV}$ of $24 \mathrm{MJ} \mathrm{kg}^{-1}$; which represents a residue with solid fuel potential. It is important that this type of pre-treatment is explored in greater depth with alternative species of seaweed and also other biomass types that are high in both water and ash, as there is clearly scope for further technological improvements that may further improve process yields.

\subsubsection{MW-assisted organosolv pre-treatment}

Pre-treatments that use organosolv are utilised to specifically target the lignin component of lignocellulosic biomass and induce delignification via the cleavage of ether linkages within the lignin complex [93]. Typically, after organosolv pre-treatment of lignocellulosic biomass, three main fractions are produced; a cellulose-rich fraction, an organosolv lignin fraction and a water soluble fraction mainly containing acid soluble lignin, sugar degradation products and hemicellulose-based monosaccharides such as galactose, xylose and arabinose [93]. A variety of different organic compounds (mainly bulk commodity chemicals) can be used as solvents in organosolv pre-treatment, including ethanol, methanol, formic acid, ethylene glycol, glycerol, acetic acid and formic acid [94].

MW-assisted organosolv pre-treatment has proved to be a versatile pre-treatment method prior to fast pyrolysis of biomass $[95,96]$. Fast pyrolysis is a thermal decomposition process involving the extremely rapid (ca. 1 second) heating of biomass in an inert environment up to temperatures around $500{ }^{\circ} \mathrm{C}$ [97]. The process results in the formation of three fractions obtained from the rapid quenching of released volatiles from the process; biochar, bio-oil and 
gas [98]. Levoglucosan is a pyrolytic by-product found in the bio-oil fraction which could either be directly fermented to bioethanol by engineered strains of Escherichia coli [99] or acid hydrolysed to glucose which is then used as a carbon source precursor for the production of ethanol via fermentation with Saccharomyces cerevisiae $[100,101]$. Figure 3 schematically outlines the process of applying MW-assisted organosolv pre-treatment to biomass prior to fast pyrolysis and possible routes of bioethanol production from levoglucosan (from the bio-oil fraction). Studies have revealed that levoglucosan can be directly produced from the fast pyrolysis of cellulose [102]. However, levels quantified in bio-oil are usually low and considered insufficient to produce high enough yields of ethanol to be economically viable. This is mainly due to the fact that cellulose in lignocellulosic biomass is trapped within a complex matrix composed of hemicellulose and lignin that are all chemically bound (Figure 4), and overcoming the high recalcitrance of this complex to access cellulose has proved to be challenging. However, MW-organosolv pre-treatment is in fact an energy-saving method (compared to conventional heating organosolv pre-treatment) that has the potential to selectively remove the lignin fraction of biomass. It also produces a pretreated residue enriched in cellulose [95]; ultimately aiding the achievement of levoglucosan yields that are close to the theoretical maximum yield (based on cellulose content). In the works of Zheng et al, corncobs [96], pine, eucalyptus and straw [103] were subjected to MWassisted organosolv pre-treatment with glycerol in an atmospheric MW reactor and the generated residues were subsequently pyrolysed. Pre-treatment parameters such as MW power and residence time were investigated in order to identify optimum conditions that would produce a pre-treated residue which when pyrolysed could yield high levoglucosan levels. This would essentially entail producing a pre-treated residue with an enriched cellulose fraction and also a low lignin content. Both studies revealed MW-assisted organosolv pre-treatment (utilising glycerol) to be an efficient method for improving the yield 
of levoglucosan liberated from the fast pyrolysis of agricultural feedstock residues. Yields of the anhydrosugar from pine, eucalyptus and straw that were each pre-treated at $150 \mathrm{~W}$ for 20 min reached as high as $33.2 \%, 59.4 \%$ and $36.0 \%$, respectively [103] and the yields from the fast pyrolysis of corncob pre-treated at $150 \mathrm{~W}$ for 18 min was almost 189 times higher than that of raw corncob [96]. Alongside the selective removal of lignin and hemicellulose, the MW-assisted organosolv pre-treatment of corncobs also aided in the removal of alkali and alkaline earth metals from the material. The authors stated that demineralisation of the biomass aided in obtaining high yields of levoglucosan. It is evident that MW-assisted organosolv pre-treatment is ideal prior to fast pyrolysis, and a wider range of organic compounds (other than purely glycerol) should be examined with a range of feedstocks in order to identify whether certain biomass feedstocks are better suited to pre-treatments with specific organic compound catalysts. Of course this would ultimately depend on knowing what specific components were to be targeted for product generation via pyrolysis.

\subsection{Bio-chemical processing}

\subsubsection{MW pre-treatment for bioethanol production via fermentation}

Bioethanol, which can be derived from sugar-based biomass through fermentation processes, is one option for the generation of energy-rich transportation fuels [104-106]. The production of bioethanol from lignocellulosic biomass generally consists of a chemical pre-treatment (acid/alkali/solvent) followed by the subsequent enzymatic hydrolysis of polysaccharides into their respective monosaccharide constituents. In this instance, the pre-treatment step is used to enhance the liberated sugar yields achieved through the enzymatic saccharification. This is then followed by the fermentation of the liberated sugars into ethanol using suitable strains of yeast, and finally the separation and purification of this bioalcohol [107]. Traditional feedstock materials such as corn, wheat and sugarcane $\left(1^{\text {st }}\right.$ generation biomass) have been widely exploited to generate bioethanol [108], however controversy over their use for fuel 
applications has led to the 'food vs fuel' debate [109]. Therefore, attention has been diverted to lignocellulosic bio-crops ( $2^{\text {nd }}$ generation biomass) and marine crops, both micro and macroalgae ( $3^{\text {rd }} /$ advanced generation biomass) as alternative feedstocks. Lignocellulosic biocrops such as wheat straw, corn stalks, wood chips and sugarcane have been well investigated in the last decade, mainly due to the fact that these plant biomasses are derived from inexpensive and abundant non-edible portions of the plant [110]. Despite the advantages $2^{\text {nd }}$ generation biomass has over first generation crops, the full potential of $2^{\text {nd }}$ generation bioethanol is yet to be fully exploited. This is because of the lignocellulosic complex and its resistance to depolymerisation (as depicted in Figure 4). Three main components form the basis of the lignocellulosic material that is found within the plant cell wall; cellulose, hemicellulose and lignin. A high degree of complexity, polymerisation, and crystallinity exists within this material and its highly amorphous structure gives rise to a complex that makes biodegradation, chemical or enzyme-based digestions challenging. The lignocellulosic material itself is considered to have been produced as a direct response to the co-evolution of plants with animals and other potential predators (such as certain microbial species) which may attempt to use the plant directly as a source of food [111]. Even though approximately $75 \%$ of the cell wall material of this plant based biomass is polysaccharide-based [112], the complex structure presents a technical barrier that needs to be overcome; making the production of biofuels from second generation crops not currently as cost effective as they could be. An overview of the industrial conversion of lignocellulosic feedstocks into fermentable sugars can be seen in Figure 5. Disruption of the lignocellulosic cell wall structure is necessary to enhance subsequent enzyme accessibility to the cell wall polymers; cellulose and hemicellulose. Physicochemical processes or 'pre-treatments' are usually applied to deconstruct the cell wall ultra-structure and disrupt the lignin-polysaccharide bonds, generating a pre-treated residue that is less recalcitrant to facilitate enzymatic 
hydrolysis and enhance the digestibility for bioethanol production [113]. Studies on MW pretreatment of lignocellulosic material are increasing and have been shown to have a positive impact on the way the lignocellulosic biomass is structurally-modified. When MW energy is applied to lignocellulosic feedstocks, selective heating of the more polar regions creates a 'hotspot' within the heterogeneous material [114]. It has been hypothesised that when lignocellulosic biomass is exposed to MW heating, 'swelling and fragmentation' effects occur internally within the biomass, which then result in the disruption of the lignocellulosic structure. This consequently results in an increase in surface area, a decrease in the degree of polymerisation and crystallinity of cellulose and the depolymerisation of lignin which ultimately improves the substrates' accessibility to enzymatic attack [115, 116]. Microwave based pre-treatments have been performed in aqueous environments, often in combination with water [117], organic solvents [118], alkali [119-121] and dilute-acid based solutions [122]. Furthermore, such pre-treatments have been shown to work effectively with a range of different lignocellulosic feedstocks, such as rape straw [122], sugarcane bagasse [123, 124], wheat straw [125, 126], sago [127] and Brewer's Spent Grains (BSG) [128, 129].

$\mathrm{NaOH}$ (alkali) pre-treatment has been applied to lignocellulosic biomass in order to remove lignin from the material and is thought to increase the porosity of the biomass by breaking the ester linkage between lignin and xylan $[130,131]$. $\mathrm{NaOH}$ has also been considered to be one of the most effective alkali reagents to combine with microwave pre-treatment of switchgrass and in an early study by $\mathrm{Hu}$ and Wen [132], a sugar yield (quantified glucose and xylose) of $58.7 \mathrm{~g} / 100 \mathrm{~g}$ of switchgrass was obtained from $\mathrm{MW}-\mathrm{NaOH}$ pre-treatment followed by enzymatic hydrolysis. Xu et al [126] identified the optimal conditions for MW-NaOH pretreatment of wheat straw according to orthogonal analysis. Pre-treatment with a solids loading content (biomass: $\mathrm{NaOH}$ ) of $80 \mathrm{~g} / \mathrm{kg}$, a $10 \mathrm{~kg} \mathrm{~m}^{-3} \mathrm{NaOH}$ concentration and microwave power of $1000 \mathrm{~W}$ for 15 min generated a liquid fraction that when fermented 
yielded an ethanol titre of $148.93 \mathrm{~g} / \mathrm{kg}$ (wheat straw), which was much higher than untreated material $(26.78 \mathrm{~g} / \mathrm{kg}$ wheat straw). A two stage MW pre-treatment on Miscanthus with ammonium hydroxide $\left(1.0 \%\right.$ [w/v] $\mathrm{NH}_{4} \mathrm{OH}, 15: 1$ liquid: solid, $120^{\circ} \mathrm{C}$ for $\left.15 \mathrm{~min}\right)$ followed by treatment with phosphoric acid $\left(1.78 \%\right.$ [v/v] $\mathrm{H}_{3} \mathrm{PO}_{4}, 15: 1$ liquid: solid, $140^{\circ} \mathrm{C}$ for $\left.30 \mathrm{~min}\right)$ liberated a total sugar yield of $71.64 \mathrm{~g} / 100 \mathrm{~g}$ (Miscanthus) [133]. The enzymatic saccharification of oil palm empty fruit bunch was significantly improved after microwave alkali pre-treatment [130]. After applying the optimum pre-treatment conditions $(3 \%$ [w/v] $\mathrm{NaOH}$ with MW heating at $180 \mathrm{~W}$ for $12 \mathrm{~min}$ ) the residue that was produced contained $74 \%$ and $25 \%$ less lignin and hemicellulose, respectively, and retained a $41 \%$ yield of total reducing sugars. The advantages of using MW heating as an alternative to conventional heating for pre-treating biomass were further highlighted in the work performed by Sudha et al [134]. Reduced pre-treatment time and also improvements in subsequent enzymatic yields during hydrolysis were observed when cassava pulp was pre-treated with dilute $\mathrm{NaOH}(1.5$ $\%$ ) at $90^{\circ} \mathrm{C}$ for $30 \mathrm{~min}$. Subsequent microwave-coupled enzymatic saccharification of the alkali pre-treated pulp with 400 IU (units of enzyme activity) $\alpha$-amylase at MW temperature of $90{ }^{\circ} \mathrm{C}$ for 1 hour resulted in the highest obtained reducing sugar yield in the study; $723 \mathrm{mg}$ sugar /g pulp compared to 328 sugar mg/g pulp that was achieved from non-pre-treated pulp. The authors demonstrated the ability of MW heating to reduce both the pre-treatment and enzymatic saccharification reaction time, which would ultimately decrease the consumption of energy needed and improve process efficiency.

MW-assisted organosolv pre-treatment using glycerol (as discussed in section 3.1.4) has also been applied to pre-treat biomass prior to enzymatic saccharification in the pursuit of bioethanol production, and it has been shown to effectively enhance delignification of terrestrial plants [135]. Due to the high boiling point temperature of glycerol and its ability to reduce the surface tension of the generated hydrolysate (the liquid fraction produced during 
pre-treatment), pre-treatments using this organic solvent have proved to be safe (even at temperatures of $290^{\circ} \mathrm{C}$ ) and efficient. Trials with sugarcane bagasse appeared to improve the digestibility of the feedstock [136]. A recent study revealed that the MW pre-treatment of corn straw using a solution of alkaline-glycerol $(95 \%[\mathrm{v} / \mathrm{v}]$ glycerol-NaOH $[1.4 \mathrm{M}]$, at $16 \%$ [w/v] solids loading, $180^{\circ} \mathrm{C}, 2 \mathrm{~min}$ ) improved the enzyme hydrolysis yields of the pre-treated biomass when using both the commercial enzyme Celluclast ${ }^{\circledR}$ and a crude enzyme extract [137]. This was the first study to report the application of a $\mathrm{NaOH}-$ glycerol co-solvent mix as a pre-treatment catalyst which induced significant surface disruptions to the biomass. SEM analysis revealed exposed trichomes (modified hair like structures found on the epidermis) and in addition the individual cells without a protoplasmic structure were also noticeable in transverse planes. Due to the abundance and low cost of glycerol (available from such sources as the production of biodiesel) its use as a pre-treatment reagent could potentially enhance techno-economic analysis (TEA) / life-cycle assessment (LCA) favourability.

The application of MW heating for the pre-treatment of biomass may be suitable for optimising processes at commercially relevant high solids loadings (the biomass to liquidreagent ratio). Wilkinson et al [129] recently revealed that auto-hydrolytical (water based) MW pre-treatment of BSG (a lignocellulosic biomass co-product from the brewing industry) could achieve glucose yields of $80-90 \%$ theoretical following treatment at $35 \%(\mathrm{w} / \mathrm{v})$ solids loading at $200{ }^{\circ} \mathrm{C}$. Similar glucose yields could also be obtained at lower temperatures of $140-160^{\circ} \mathrm{C}$ with the addition of $1 \%(\mathrm{w} / \mathrm{v}) \mathrm{HCl}$, as the acid catalyst acts to enhance the hydrolysis mechanism through the provision of the additional protons. The acid catalysed pre-treatment of BSG at higher solids loadings contents of 40-50\% (w/v) were also investigated, however higher temperatures of $180-200^{\circ} \mathrm{C}$ were then necessary in order to maintain high sugar yields. Therefore, careful consideration is needed to conclude whether operation (pre-treatment) at high solids loading warrants the high input of energy. Operating 
at higher solids loadings clearly enables a greater degree of biomass processing per batch (thus per unit time) which may again improve LCA and TEA favourability.

\subsubsection{MW pre-treatment for biogas production via anaerobic digestion}

Anaerobic digestion (AD) is a biological process that converts complex biological substrates into both biogas (biomethane) and a waste digestate, in the absence of oxygen by a consortium of bacteria [138, 139]. It is one of the oldest and most well-studied process technologies involved in the stabilisation of organic wastes, and is a highly suitable technology for treating organic solid wastes because of its limited environmental impact and high energy recovery potential [140]. The process is comprised of four main steps, namely hydrolysis, acidogenesis, acetogenesis and methanogenesis (Figure 6). During hydrolysis, the polymers that make up the organic matter, fats, proteins and carbohydrates, are broken down extracellularly into their respective monomers of fatty acids, glycerol, amino acids and simple sugars. The monomers are then up-taken and fermented by acidogenic bacteria into alcohols and organic acids such as proprionic acid, acetic acid, formic acid, ethanol and butyric acid, as well as some carbon dioxide and water [141]. Some of these substrates are then converted into acetic acid, plus hydrogen and carbon dioxide by acetogenic bacteria. For example, proprionic acid is converted to acetic acid (plus hydrogen and carbon dioxide), and ethanol and butyric acid are converted to acetic acid and hydrogen. The process could then be terminated at this stage to just produce hydrogen and carbon dioxide gas; however the incorporation of methanogenic bacteria will then result in the additional production of methane (as well as carbon dioxide and water), and possibly some hydrogen sulphide.

A range of different feedstocks and/or waste materials can be converted into biogas via anaerobic digestion, including sludge, food waste, manure, lignocellulosic biomass and algae [142]. The hydrolysis step is typically regarded as the 'rate limiting' step, usually requiring 
some form of pre-treatment in order to improve the effectiveness of the anaerobic digestion process and to enhance the kinetics of the overall process [143]. Pre-treatment may assist in the breakdown of the larger complex polymers into smaller molecules, which promotes hydrolysis [144]. In the case of waste activated sludge (WAS) for example, the material itself is already composed of a diverse range of microorganisms and organic and inorganic compounds which are agglomerated together in a polymeric network formed by extracellular polymeric substances (EPS) that include proteins, carbohydrates and volatile fatty acids [145]. The efficiency of the hydrolysis step of WAS AD is strongly influenced by the presence of EPS and in order to overcome this rate restricting step (that is enforced by EPS complexes), pre-treatment techniques are applied to enhance its digesting capability [146] and make the substrate more amenable for AD. In theory, the application of pre-treatment disrupts the sludge flocs, disintegrates the bacterial cell walls and transfers the EPS, intracellular organic matter and divalent cations into the liquid phase of the WAS; thus enhancing sludge biodegradability [147] and ultimately reduces hydraulic retention time (the amount of time the feedstock spends inside the digester) [148]. Microwave heating has been successfully applied to pre-treat biomass or sludge for subsequent AD. The technology has proved to enhance the overall process $[149,150]$ by increasing biogas production, reducing sludge viscosity, and has been found to increase the ratio of soluble chemical oxygen demand (SCOD) to total chemical oxygen demand (SCOD/TCOD) from $2 \%$ to $22 \%$ [151]. It is thought that through the combined effects of both a more rapid increase in temperature (when using MWs) and the rapidly changing dipole orientation in the polarised side chains of the cell membrane macromolecules, compounds disintegrate via the breakage of the hydrogen bonds $[152,153]$. Studies have suggested that MW pre-treatment of municipal sewage sludge can improve sludge de-waterability [154], reduced faecal coliform (potential human 
pathogenic species) counts in the sludge [155] and most importantly increased the overall production of biogas [156].

Ebenezer et al [157] investigated the option of improving the efficiency of the MW pretreatment of WAS via sludge deflocculation. Deflocculation occurs when a monocovalent cation, such as $\mathrm{Na}^{+}$, is introduced into the activated sludge medium and removes bridging ions like $\mathrm{Ca}^{2+}, \mathrm{Mg}^{2+}, \mathrm{Fe}^{2+}$ and $\mathrm{Fe}^{3+}$ which results in the release of EPS from the flocs. Sodium tripolyphopshate (a cation binding agent) was used which resulted in a MW specific reduction in energy required from 26,000 to $14,000 \mathrm{~kJ} / \mathrm{kg}$ TS (total solids). This resulted in a $50.7 \%$ decrease in the cost of the MW pre-treatment. The deflocculated sludge was then subjected to MW pre-treatment in order to assess the impact on biomass disintegration. Deflocculation of the sludge followed by MW heating facilitated an increase in sludge disintegration efficiency when compared to MW heating alone: COD solubilisation increased from $21 \%$ (when using MW heating alone) to $28 \%$ (deflocculation plus MW heating) and the reduction in suspended solids significantly increased from $22 \%$ to $38 \%$.

Optimisation of MW pre-treatment of wheat grass for enhanced solubilisation and increase in biodegradability was performed by [125]. Temperature, ramp time and holding time at the targeted temperature were all investigated in order to improve $\mathrm{AD}$ effectiveness whilst minimising costs. Optimal conditions (which resulted in a $28 \%$ enhancement in methane) for MW pre-treatment were concluded to require a final temperature of $150^{\circ} \mathrm{C}$. Interestingly, variation in the ramp time and hold time at certain targeted temperatures did not show any improvements in methane yields.

In order to alleviate the overall costs and reduce the high energy demand that is associated with the use of MW for cell disintegration in $\mathrm{AD}$, a variety of combinative pre-treatment methods have been investigated. These include combinations of chemicals such as acids 
[158], alkali [159-161] and $\mathrm{H}_{2} \mathrm{O}_{2}$ [162, 163]. Microwave heating was coupled with alkali treatment in work conducted by Chang et al [164], who suggest that the combined pretreatment (600W for $2 \mathrm{~min}$ and $14.5 \mathrm{~g} / \mathrm{L} \mathrm{NaOH}$ dose for $10 \mathrm{~min}$ ) synergistically enhanced the COD solubilisation (46\% increase) from waste activated sludge. This value was equivalent to almost a two-fold increase compared to the combined values obtained by either MW pretreatment alone $(8.5 \%)$ or alkali pre-treatment alone $(18 \%)$.

Advanced oxidation processes (AOP) have also been coupled with MW heating for the pretreatment of sludge. The process relies on the generation of reactive free radicals; in particular hydroxyl radicals $\left({ }^{\bullet} \mathrm{OH}\right)$, as these powerful oxidising agents have the potential to increase the rate of many deconstructive reactions and ultimately reduce the operational costs of a process [29]. It has been suggested that an increase in reaction temperature during MW heating induces the formation of ${ }^{\bullet} \mathrm{OH}$, which then destructs the cell walls and membranes of the EPS complex and the breakage of DNA strands [165, 166]; and these synergistically improve the disintegration of sludge. Table 2 summarises the major findings of the work undertaken to investigate the influence of MW-AOP pre-treatment on WAS. Xiao et al [162] reported that SCOD increased by 30.5 times after $\mathrm{MW}-\mathrm{H}_{2} \mathrm{O}_{2}$ pre-treatment of sludge, which was more efficient than both MW pre-treatment alone and combinative MW-acid/alkali pretreatment methods. Research into the rheological characteristics of the sludge generated after pre-treatment with $\mathrm{MW}-\mathrm{H}_{2} \mathrm{O}_{2}$ was conducted by Liu et al [167]. The rheological properties of sludge may influence sludge management, treatment and downstream hydrodynamic processes involved in $\mathrm{AD}$ (such as mixing, pumping and recirculating [168]). The group concluded that $\mathrm{AD}$ of sludge combined with $\mathrm{MW}-\mathrm{H}_{2} \mathrm{O}_{2}$ pre-treatment improved the fluid dynamics and weakened the elastic properties of sludge. As a result of the $\mathrm{MW}-\mathrm{H}_{2} \mathrm{O}_{2}$ pretreatment the strength of the inner structures and the non-Newtonian flow characteristics of the digested sludge weakened in strength, and additionally variation in the composition of the 
EPS was also noticed; i.e. variation of the ratio of proteins and polysaccharides. This work highlighted $\mathrm{MW}-\mathrm{H}_{2} \mathrm{O}_{2}$ pre-treatment as a favourable combination with AD. However, research has revealed that large amounts of residual $\mathrm{H}_{2} \mathrm{O}_{2}$ remain in the AD system after pretreatment, and subsequent AD stages are inhibited due to its toxic effect on cells [160]. Liu et al [158] evaluated the effects of residual $\mathrm{H}_{2} \mathrm{O}_{2}$ on the hydrolysis-acidification and methanogenesis stages of $\mathrm{AD}$ after $\mathrm{MW}-\mathrm{H}_{2} \mathrm{O}_{2}$ pre-treatment of municipal sludge. Despite achieving a high COD solubilisation, there was ultimately no enhancement in methane production and the negative effects gave rise to a longer lag phase and a low methane production rate. Furthermore, an inhibitory effect was observed on the metabolic activity of methanogens and mildly affected the hydrolysis-acidification stage of AD. This work demonstrated the importance of pre-treatment dosage control and optimisation, and most imperatively, an understanding of how pre-treatment catalysis chemicals can affect the biology of the chosen energy conversion route system. The $\mathrm{pH}$ of sludge after $\mathrm{MW}-\mathrm{H}_{2} \mathrm{O}_{2}$ pretreatment is normally in the alkaline range ( $\mathrm{pH}$ 9-10), possibly making the sludge unfavourable for subsequent $\mathrm{AD}$ as the chances of methanogen inhibition increases and hence methane production is terminated. Eswari et al [169] included the addition of acid in the MW- $\mathrm{H}_{2} \mathrm{O}_{2}$ pre-treatment combination (at an optimum specific energy of $18,600 \mathrm{~kJ} / \mathrm{kg} \mathrm{TS}$ ) in order to balance out the deleterious effects which are implicated by the alkaline environment (as a $\mathrm{pH}$ adjustment mechanism). The sludge solubilisation increased up to $56 \%$ and a maximum methane production of $323 \mathrm{~mL} / \mathrm{g}$ volatile solids was achieved. Furthermore, cost analysis of the process was deduced to be both economically and energetically feasible with a net profit of $59.90 € /$ tonne of sludge.

Studies have explored microalgae as a potential feedstock for the production of biogas via AD. The majority of the research that has been undertaken with microalgae production and processing has mainly been focussed on the generation of biodiesel and biogas. However, the 
energy demand and the economic impacts involved in biomass drying and the extraction of the lipid content from the microalgal cells are not sustainable and may not be economically viable to perform at commercial scale [170]. AD offers an alternative option for converting microalgal biomass in its entirety (without the need for any prior drying for water removal and/or prior pre-treatment steps) into a final product of useable energy [171]. Nevertheless, due to the complex structure and composition of the microalgal cell wall which hinders the initial hydrolysis step, pre-treatment methodologies have also been applied to improve the ultimate methane production yields and the biodegradability of the biomass [172]. In the work of Passos et al [173], the specific energy (regardless of the output power and exposure time) of the MW pre-treatment on microalgae biomass cultivated in High Rate Algal Ponds (HRAP), played an important effect on biomass solubilisation and final methane yields. Biochemical methane production tests revealed that use of an optimal pre-treatment increased biomass solubilisation by $8 \%$ and the methane yield by $78 \%$. MW pre-treatment was also evaluated in continuous anaerobic reactors operating at Hydraulic Retention Times (HRT) of 15 and 20 days, to assess the effects on microalgal cell disruption and biogas production [174]. MW pre-treatment enhanced the methane yields by $30 \%$ at 15 days HRT and by $58 \%$ at 20 days HRT. Additionally, microscopic images (both optic and TEM) revealed that some microalgal cell walls remained still intact after microwave pre-treatment whilst others had lysed. However, the internal organelles in the intact cells appeared to be damaged beyond repair. This most likely contributed towards the improved anaerobic biodegradability of the microalgae. Nevertheless, the high consumption of energy that was required for this MWbased pre-treatment was a major disadvantage of this technique and the authors suggested that alternative, lower energy consuming pre-treatments ought to be investigated. 


\section{Opportunities, future direction and recommendations for microwave research}

It is evident that the application of MW heating has proved to be advantageous for the pretreatment of various biomass feedstocks across numerous bioenergy conversion routes and biomass upgrading processes when compared to traditional conventional heating methods. MW heating has the potential to overcome and avoid many of the problems that are traditionally associated with conventional heating methodologies and the unique heating (and processing) characteristics exhibited by MWs have allowed researchers to identify numerous options for biomass pre-treatment and upgrading processes. Table 3 summarises the opportunities that are associated with the application of MWs to pre-treat and upgrade biomass, alongside additional features that would ideally be included within each protocol. Although MW heating has many incentives to be incorporated into pre-treatment and upgrading process, there are a number of challenges that are yet to be addressed and fully understood. These include the understanding of energy balances, deciphering the fundamentals behind induced temperature gradients within the 'heated' biomass and importantly the dielectric properties of different feedstocks. Consequently, despite the wealth of research which has shown the unique benefits of MW heating, the growth of industrial MW heating applications is somewhat limited by an apparent lack of fundamental understanding of the MW heating system, in addition to the technical information required for commercial design and development. In light of the latter, potential solutions are emerging and novel MW scalable processing concepts have been reviewed [175]. This section of the review identifies and discusses the main issues and challenges associated with this heating technique, and the future directions this area of research requires to exploit the full potential of this heating technique. 


\subsection{Dielectric properties of biomass}

MW heating is dependent on the interaction of electromagnetic energy with biomass, and the ability of the material to absorb and convert this energy into heat [176]. There is clearly a lack of fundamental data on the dielectric properties of biomass and its individual constituents, however it is vital that such parameters are studied and understood in order to understand the heating behaviour and thermal gradients that can exist within different systems [177]. To date, there are only a small number of publications which report the dielectric properties of a small selection of biomass types. These include sorghum [178], oil palm [179-181], Australian wood-based biomass [182], wood pellets [183], Tobacco stems [184], hay [185], switchgrass [186] and corn stover [187]. However, the majority of these studies have only acquired dielectric property measurement information at temperatures up to ca. $50^{\circ} \mathrm{C}$. It is known that the dielectric properties of biomass change nonlinearly with temperature [183], however only a limited number of studies have determined the dielectric properties of biomass at elevated temperatures (within the $100^{\circ} \mathrm{C}-900^{\circ} \mathrm{C}$ temperature range) $[176,185,186,188,189]$. Considering that the pre-treatment of biomass may require temperatures that exceed $100^{\circ} \mathrm{C}$ (for example biomass torrefaction requiring temperatures up to $300^{\circ} \mathrm{C}$ ), further work is required to determine the dielectric responses of different biomass feedstocks at higher temperatures. This may then allow for the specific adjustment of optional parameters to further improve MW heating efficiencies, and thus further reduce the energy input for the pre-treatment step whilst still maintaining its efficacy [129]. Furthermore, dielectric property data would enable the design of MW processing systems for different biomass feedstocks as well as for process design calculations that involve various heat-based unit operations [178].

Whilst the authors acknowledge very few research groups and laboratories have both the equipment and trained personnel to conduct dielectric property measurements, this data is 
fundamentally essential for successful commercial development of MW based processing. This potentially highlights the requirements for greater collaboration between different research groups (for example greater interdisciplinary collaborations between electromagnetic scientists, engineers and bio-scientists) in order to achieve this and to bridge the gap between fundamental research and to eventually roll out the application commercially. Furthermore, by understanding the dielectric properties of input feedstocks the design and development of MW-based pre-treatment units can be performed in a much more accurate, effective and economical way.

\subsection{Microwave apparatus and the importance of cavity design}

The majority of the aforementioned studies in this review report the use of domestic MW ovens which have been modified to internally contain open beakers/flasks for placing biomass (and possibly the reactant), to serve as reactors for atmospheric pressure MW pretreatments. Conversely, when higher temperature pre-treatments are conducted $\left(\geq 150^{\circ} \mathrm{C}\right)$, a more robust system is required and experiments are usually performed in closed reactors which can withstand the high pressure build up that often occurs. Examples of the latter include the Anton Paar Monowave 300 microwave synthesis reactor (Anton Paar Gmbh, Graz, Austria) and the Discover LabMate System from CEM Corporation (Buckingham, UK) which feature built-in agitation devices, temperature monitoring/control of the reaction mixture with either infrared sensors or fibre optic probes and software which enables the user to monitor the temperature/pressure of the reaction [190]. However, one of the main limitations with such devices (and also a limitation of domestic MW ovens) is the relatively low intensity electric field and the absence of reflected power measurements. Energy balances reported for such equipment therefore need to be interpreted with caution, as it is not possible to determine the energy absorbed by the sample. The low intensity electric field has 
implications for the power absorbed per unit volume (otherwise termed power density [Pd]), which can be defined by the following equation for a uniform electric field:

$P d=2 \pi f \varepsilon_{0} \varepsilon^{\prime \prime}|E|^{2} \quad[2]$

where $f$ is the MW frequency, $\varepsilon_{0}$ is the permittivity of free space $\left(8.85 \times 10^{-2} \mathrm{~F} / \mathrm{m}\right), \varepsilon^{\prime \prime}$ is the dielectric loss factor and $E$ is the magnitude of the electric field. Selective heating of biomass constituent components material can be induced in a MW environment if the material that is being heated contains a mixture of absorbent and transparent phases, however conventional heat transfer also occurs simultaneously. If the power density is low (due to low electric field intensity) then conventional heat transfer can dominate, leading to low or negligible thermal gradients within the biomass and a situation that is comparable to conventional heating. At high power densities volumetric heating dominates over conventional heat transfer, leading to significant thermal gradients and therefore the ability of MW heating to treat biomass in a way that is not possible with conventional heating. Biomass usually contains moisture (water), which will easily absorb MWs at room temperature, however upon heating and after the water is lost, biomass will become increasingly transparent to MWs when temperatures are raised [183]. In this case it is important that a high electric field intensity is used in order to induce further decomposition of the biomass after the initial loss of water, something that is not possible with domestic microwave ovens and has led researchers to use microwavesusceptors to achieve high temperatures in this equipment. The use of susceptors leads to the heating of biomass by conventional heat transfer, and therefore does not create the thermal gradients within the biomass that exist when high intensity electric fields are used.

As well as the intensity of the electric field, the distribution within the MW cavity itself also needs to be understood. A unique characteristic of MW heating is the formation of 'hot spots', which arise from the inherent heterogeneity of the electric field within a cavity [33]. 
Hot spots are formed where the MW field strength is highest [77]. Figure 7 shows an illustrative example of a single hot spot distributed inside a single mode cavity with a vessel holding biomass undergoing pre-treatment. The Figure illustrates that the hot spot is not evenly located across the biomass, suggesting that there would be an uneven distribution of heat across the biomass and the degree of pre-treatment would not be consistent. Ultimately this would produce a residue with only partly pre-treated regions and if this residue was to undergo subsequent enzymatic saccharification for the liberation of monosaccharides (namely glucose which could subsequently be fermented to bioethanol), the efficacy of this saccharification would likely be affected. The authors suggest that this could be due to the lack of 'exposed' binding sites that are compatible with the enzymes that have the ability to cleave $\beta-1,4$ linkages along the exposed cellulose polymer. As such, sub-optimal glucose yields could be achieved and overall low yields of bioethanol would be produced. Therefore, it is imperative that the pre-treatment of biomass is as effective as possible, as this step is considered to be the most rate limiting, energy intensive and expensive for bioenergy production. Unfortunately, there is a poor understanding of the distribution of the electromagnetic field within domestic and single mode MW cavities, and to date there has been no investigation of the effects of MW frequency, power and biomass position (in the cavity) on the biomass temperature and dielectric field distribution. Ideally, mapping the power density distribution (preferably in real time) as the feedstock is being pre-treated, (whether for drying purposes, torrefaction, or to induce the necessary structural alternations for increased hydrolysis efficacy for bioethanol or $\mathrm{AD}$ conversion routes) would further aid in the development of biomass pre-treatment processes using MW heating. Robinson et al [190] investigated the phenomena that occur within a MW single mode cavity using electromagnetic simulations and heating experiments to show the effects of different factors (including solvent type, vessel material and stirring rate) on the distribution of the electric 
field, power density and rate of heating. It was noticed that around the edges of internal protruding objects (such as stirrers and temperature probes) the electric field and power density were significantly concentrated (Figure 8). Furthermore, the volume of solvent present in a reaction vessel has an effect on the distribution of the electric field [190]. However, considering that researchers have often attempted to optimise experimental parameters including the biomass to solvent volume ratio on the rate of reactions, product yields or biomass digestibility [109, 129, 133, 137], the electric field distribution has almost always been overlooked. Uneven distributions of the electric field can induce large thermal gradients and localised heating effects (hot spots) which would have a significant influence on the pre-treated residue generated. In order to control the occurrence of hot spots and localised heating, cavity design is an essential factor to consider [33]. There are several techniques that could be employed to overcome the effects of hot spots, which include changing the geometry of the cavity by modifying its size, using multiple MW inputs, operating at higher frequencies and ensuring adequate heterogeneity of the material [191].

Whilst the majority of reported studies utilise microwave heating equipment operating at a frequency of $2.45 \mathrm{GHz}$, the electrical efficiency of these systems is typically only around 40\%. This low efficiency renders the $2.45 \mathrm{GHz}$ operating frequency unsuitable for the majority of industrial applications, except in cases where very high value products are being produced. Most industrial microwave heating equipment operates at a frequency between 896 - $922 \mathrm{MHz}$, and in this case the electrical efficiency is typically around 85\% [177]. The use of $2.45 \mathrm{GHz}$ equipment within the laboratory-environment is of considerable value for the assessment of heating effects and opportunities for the technology for different feedstocks, however it is important that scale-up and economic considerations are based on the use of the lower frequency range. 


\subsection{Temperature control and monitoring}

An important yet often overlooked issue faced with MW heating technologies is the accurate and representative measurement of temperature. The majority of previous work has used grounded thermocouple probes; which are contact-type sensors. These probes are still used despite the fact that grounded thermocouples are metallically shielded, and can significantly distort the electric field [190]. The act of attempting to measure the temperature therefore distorts the actual temperature within the vicinity of the probe. A study conducted by Satpathy et al [74] investigating the effects of different power levels and process times on the torrefaction of biomass noticed that temperature measurements were not completed for 300 $\mathrm{W} / 20 \mathrm{~min}$ for wheat straw and $250 \mathrm{~W} / 20 \mathrm{~min}$ and $300 \mathrm{~W} / 15-20 \mathrm{~min}$ for barley straw. This was because the group had noticed that the Teflon coating on the thermocouple had melted at those process conditions (as the temperature had reached $>400^{\circ} \mathrm{C}$ ). Due to this unreliability and also the possible chances of destruction of the temperature probes, data interpretation should, where possible, avoid the reliance on temperature measurements and possibly be reported as a function of MW power density or energy input as an alternative. In response, researchers have resorted to use infrared optical pyrometers in combination with grounded thermocouple probes to improve the reliability of temperature measurements [27], however these only give an indication of the surface temperature. The thermal gradients that are present within materials such as biomass due to the combination of selective and volumetric heating cannot be measured, and therefore any reported temperature values must be interpreted with caution.

\subsection{Understanding selective heating behaviour}

One of the major challenges associated with MW heating for biomass processing is ensuring there is sufficient absorption of the MWs by the target material to induce the required thermal gradients. Biomass contains a mixture of phases that are both MW absorbent and MW 
transparent, and their heterogeneous nature needs to be considered and understood in order to successfully develop and scale up MW pre-treatment and/or upgrading processes. The thermal behaviour of biomass is strongly dependent upon the biochemical composition and structure of the feedstock, and the specific effects of MW heating on biomass has been previously explored [192-194]. Within the biomass, not all of the biochemical constituents are able to absorb MWs, and even if they can absorb MWs, the degree of polarisation (induced by MW heating) would depend heavily on the polarity of side groups found on each macromolecule. Nonetheless, there is still considerable controversy regarding fundamental understandings behind the mechanistic links surrounding the physico-chemical aspects of MW heating and biomass. MWs heat biomass almost instantaneously due to the presence of free water, but soon after the biomass becomes less MW absorbent. Some authors have suggested that superheating of capillary and bound water creates a pressure build up within the biomass structure, which then induces temperatures in excess of $200^{\circ} \mathrm{C}$, required for driving thermochemical pre-treatment processes (such as torrefaction and drying based processes) [183, 195-197]. The bulk heating mechanism of microwave irradiation causes water to vaporise within the pores of the biomass, as water dipoles attempt to continuously reorient within the oscillating electric field. An energy loss by heating is attained when the water dipole lags behind the electric field, and water transport can be then promoted selectively, as water is much higher microwave absorbing than the main constituents of lignocellulosic material.

Nevertheless, the abilities of the different biochemical components may also simultaneously play a key role in the absorption of MWs. The rigidity of structures in crystalline regions (of certain macromolecules such as cellulose) also restrict the ability of molecules to become aligned with the electric field; facilitating only amorphous regions to become aligned with the applied electric field [198]. The MW heating mechanism and decomposition of cellulose, one 
of the most abundant nature polymers and a major constituent of lignocellulosic biomass was investigated by Budarin et al [192]. The group proposed that at $180^{\circ} \mathrm{C}$ the amorphous region of cellulose softens and enables a MW induced rearrangement. The number of side groups capable of rotating increases which essentially then enhances the degree of molecular freedom and the groups can align with the oscillating electric field. There is very limited information available about the behaviour of lignin and hemicellulose under MW heating. Understanding the behavioural differences between the major components found within feedstocks and their dielectric properties would aid in the design of scalable processes and development of the technology. This would, however, be an extremely complex task especially since the biochemical compositions of different feedstocks and wastes significantly differ between one another. This is in part due to the biosynthesis of the macromolecular constituents often occurring via random polymerisation generating both highly amorphous and variable polymers. Yet full and accurate characterisation is imperative. Targeting the components within biomass and waste residues for dielectric property determination would be a suitable approach to gain a fundamental understanding of how they each behave under MW heating. However, this may not be truly indicative of their actual dielectric behaviour due to the differences between pure substrate model systems and the biochemical constituents that are embedded within a complex biomass matrix.

\section{Conclusions}

Reviews of the latest publications have shown great advances, widespread applications and an ever growing interest in the use of MW heating to pre-treat different biomass types and waste feedstocks across various bioenergy conversion routes and for biomass upgrading. Studies have shown that this heating technique can be both a sustainable and energy efficient option for effective biomass to biofuel and biochemical conversion, which consequently could reduce overall processing costs if this technology was to be implemented. However, 
due to a clear gap between understanding the specific fundamentals of the MW heating mechanism with biomass and wastes, the technology has struggled to proceed beyond laboratory scale experimental apparatus to industrially scaled processes. Although the science behind the many published research articles in this area is novel and has had impact and made significant contributions of knowledge to the scientific community, the background behind the electromagnetic interaction with biomass and wastes has often been overlooked. For various pre-treatment processes such as MW-drying, there is a definitive mechanistic link between the physico-chemistry of the process and the application of MWs which has enabled this process to become commercial on an industrial scale. Nevertheless, the lack of a clear understanding of the interaction of the electric field and the biomass in other pre-treatment processes has hindered their industrialisation. The optimisation of MW based processes and their subsequent scale up to commercial scale will then be dependent upon how well the process parameters and their interactions are understood. Multidisciplinary groups and collaborations between research groups are key and are required to pursuit this exciting area of research and answer the challenging questions associated with MW heating and biomass pre-treatment/upgrading technologies.

\section{Acknowledgements}

Dr. Emily Kostas would like to thank Dr. Tamara Monti for helpful and insightful discussions about electromagnetics and Dr. Stuart Wilkinson for help with proofing. This work did not receive any specific grant from funding agencies in the public, commercial, or not-for-profit sectors. 


\section{References}

1. Bauen, A., et al., Bioenergy: a sustainable and reliable energy source. A review of status and prospects. Bioenergy: a sustainable and reliable energy source. A review of status and prospects, 2009.

2. McKendry, P., Energy production from biomass (part 1): overview of biomass. Bioresource technology, 2002. 83(1): p. 37-46.

3. Osamu, K. and H. Carl, Biomass handbook. Gordon Breach Science Publisher, 1989.

4. Bioenergy, I., Potential contribution of bioenergy to the world's future energy demand. IEA Bioenergy: ExCo, 2007. 2007: p. 02-12.

5. Proskurina, S., et al., Five years left-How are the EU member states contributing to the $20 \%$ target for EU's renewable energy consumption; the role of woody biomass. Biomass and Bioenergy, 2016. 95: p. 64-77.

6. AEBIOM, Statistical Report - European Bioenergy Outlook. European Biomass Association, 2015. http://www.aebiom.org/library/statistical-reports/statistical-report-2015/.

7. Nigam, P.S. and A. Singh, Production of liquid biofuels from renewable resources. Progress in energy and combustion science, 2011. 37(1): p. 52-68.

8. Faaij, A., Modern biomass conversion technologies. Mitigation and adaptation strategies for global change, 2006. 11(2): p. 335-367.

9. Searcy, E., et al., The relative cost of biomass energy transport, in Applied Biochemistry and Biotecnology. 2007, Springer. p. 639-652.

10. Ogura, K., et al., Pretreatment of Japanese cedar by ionic liquid solutions in combination with acid and metal ion and its application to high solid loading. Biotechnology for biofuels, 2014. 7(1): p. 1.

11. Behera, S., et al., Importance of chemical pretreatment for bioconversion of lignocellulosic biomass. Renewable and Sustainable Energy Reviews, 2014. 36: p. 91-106.

12. Alvira, P., et al., Pretreatment technologies for an efficient bioethanol production process based on enzymatic hydrolysis: a review. Bioresource technology, 2010. 101(13): p. 48514861.

13. Keshwani, D.R. and J.J. Cheng, Modeling changes in biomass composition during microwavebased alkali pretreatment of switchgrass. Biotechnology and bioengineering, 2010. 105(1): p. 88-97.

14. Lynd, L.R., Overview and evaluation of fuel ethanol from cellulosic biomass: technology, economics, the environment, and policy. Annual review of energy and the environment, 1996. 21(1): p. 403-465.

15. Lynd, L.R., R.T. Elamder, and C.E. Wyman, Likely features and costs of mature biomass ethanol technology. Applied biochemistry and biotechnology, 1996. 57(1): p. 741-761.

16. Yang, B. and C.E. Wyman, Pretreatment: the key to unlocking low-cost cellulosic ethanol. Biofuels, Bioproducts and Biorefining, 2008. 2(1): p. 26-40.

17. Singh, R., et al., A review on delignification of lignocellulosic biomass for enhancement of ethanol production potential. Renewable and Sustainable Energy Reviews, 2014. 32: p. 713728.

18. Puligundla, P., S.-E. Oh, and C. Mok, Microwave-assisted pretreatment technologies for the conversion of lignocellulosic biomass to sugars and ethanol: a review. Carbon letters, 2016. 17(1): p. 1-10.

19. Anastas, P. and J. Warner, Green chemistry. Frontiers, 1998.

20. Richel, A. and N. Jacquet, Microwave-assisted thermochemical and primary hydrolytic conversions of lignocellulosic resources: a review. Biomass Conversion and Biorefinery, 2015. 5(1): p. 115-124.

21. Banik, S., S. Bandyopadhyay, and S. Ganguly, Bioeffects of microwave--a brief review. Bioresource technology, 2003. 87(2): p. 155-159. 
22. Motasemi, F. and F. Ani, A review on microwave-assisted production of biodiesel. Renewable and Sustainable Energy Reviews, 2012. 16(7): p. 4719-4733.

23. Nüchter, M., et al., Microwave assisted synthesis-a critical technology overview. Green chemistry, 2004. 6(3): p. 128-141.

24. Kappe, C.O., A. Stadler, and D. Dallinger, Microwaves in organic and medicinal chemistry. 2012: John Wiley \& Sons.

25. Von Hippel, A.R., Dielectrics and waves. 1954.

26. Hippel, A.v., Dielectric materials and applications. London: Artech House, 1954.

27. Motasemi, F. and M.T. Afzal, A review on the microwave-assisted pyrolysis technique. Renewable and Sustainable Energy Reviews, 2013. 28: p. 317-330.

28. Kappe, C.O., Controlled microwave heating in modern organic synthesis. Angewandte Chemie International Edition, 2004. 43(46): p. 6250-6284.

29. Remya, N. and J.-G. Lin, Current status of microwave application in wastewater treatmenta review. Chemical Engineering Journal, 2011. 166(3): p. 797-813.

30. Yin, C., Microwave-assisted pyrolysis of biomass for liquid biofuels production. Bioresource technology, 2012. 120: p. 273-284.

31. $\mathrm{Li}, \mathrm{H}$. , et al., Microwave irradiation-A green and efficient way to pretreat biomass. Bioresource technology, 2016. 199: p. 34-41.

32. Chaturvedi, V. and P. Verma, An overview of key pretreatment processes employed for bioconversion of lignocellulosic biomass into biofuels and value added products. 3 Biotech, 2013. 3(5): p. 415-431.

33. Jones, D., et al., Microwave heating applications in environmental engineering-a review. Resources, conservation and recycling, 2002. 34(2): p. 75-90.

34. Suresh, K., et al., Mechanistic investigations in sono-hybrid techniques for rice straw pretreatment. Ultrasonics sonochemistry, 2014. 21(1): p. 200-207.

35. Singh, S., et al., Mechanistic investigation in ultrasound-assisted (alkaline) delignification of Parthenium hysterophorus biomass. Industrial \& Engineering Chemistry Research, 2014. 53(37): p. 14241-14252.

36. Bharadwaja, S., S. Singh, and V.S. Moholkar, Design and optimization of a sono-hybrid process for bioethanol production from Parthenium hysterophorus. Journal of the Taiwan Institute of Chemical Engineers, 2015. 51: p. 71-78.

37. Borah, A.J., et al., Mechanistic investigation in ultrasound induced enhancement of enzymatic hydrolysis of invasive biomass species. Bioresource technology, 2016. 213: p. 342349.

38. Zhang, X., Q. Yuan, and G. Cheng, Deconstruction of corncob by steam explosion pretreatment: Correlations between sugar conversion and recalcitrant structures. Carbohydrate Polymers, 2017. 156: p. 351-356.

39. Chen, H.Z. and Z.H. Liu, Steam explosion and its combinatorial pretreatment refining technology of plant biomass to bio-based products. Biotechnology journal, 2015. 10(6): p. 866-885.

40. Kataria, R., et al., Bench scale steam explosion pretreatment of acid impregnated elephant grass biomass and its impacts on biomass composition, structure and hydrolysis. Industrial Crops and Products, 2016.

41. Mathew, A.K., et al., An evaluation of dilute acid and ammonia fiber explosion pretreatment for cellulosic ethanol production. Bioresource Technology, 2016. 199: p. 13-20.

42. Hoover, A.N., et al., Effect of pelleting process variables on physical properties and sugar yields of ammonia fiber expansion pretreated corn stover. Bioresource technology, 2014. 164: p. 128-135.

43. Gao, X., et al., Comparison of enzymatic reactivity of corn stover solids prepared by dilute acid, AFEX ${ }^{T M}$, and ionic liquid pretreatments. Biotechnology for biofuels, 2014. 7(1): p. 71. 
44. Zheng, J. and L. Rehmann, Extrusion pretreatment of lignocellulosic biomass: a review. International journal of molecular sciences, 2014. 15(10): p. 18967-18984.

45. Chen, X., et al., Enhancing methane production from rice straw by extrusion pretreatment. Applied Energy, 2014. 122: p. 34-41.

46. Moro, M.K., et al., Continuous pretreatment of sugarcane biomass using a twin-screw extruder. Industrial Crops and Products, 2017. 97: p. 509-517.

47. Antonetti, C., et al., Novel microwave synthesis of ruthenium nanoparticles supported on carbon nanotubes active in the selective hydrogenation of $p$-chloronitrobenzene to $p$ chloroaniline. Applied Catalysis A: General, 2012. 421: p. 99-107.

48. Tsubaki, S., Y. Ozaki, and J.-i. Azuma, Microwave-Assisted Autohydrolysis of Prunus mume Stone for Extraction of Polysaccharides and Phenolic Compounds. Journal of food science, 2010. 75(2): p. C152-C159.

49. Tsubaki, S., M. Sakamoto, and J.-i. Azuma, Microwave-assisted extraction of phenolic compounds from tea residues under autohydrolytic conditions. Food Chemistry, 2010. 123(4): p. 1255-1258.

50. Roos, C.J., Biomass drying and dewatering for clean heat \& power. 2008: Northwest CHP Application Center.

51. Mujumdar, A.S. and C.L. Law, Drying technology: Trends and applications in postharvest processing. Food and Bioprocess Technology, 2010. 3(6): p. 843-852.

52. Oasmaa, A. and S. Czernik, Fuel oil quality of biomass pyrolysis oils state of the art for the end users. Energy \& Fuels, 1999. 13(4): p. 914-921.

53. Teixeira, C., et al., Evaluation of The Potential of Fruit Peel Biomass After Conventional and Microwave Drying for Use as Solid Fuel. 2015.

54. Wang, X., et al., The Influence of Microwave Drying on Biomass Pyrolysist. Energy \& Fuels, 2007. 22(1): p. 67-74.

55. Al Rey, C.V., et al., Microwave drying characteristics of microalgae (Chlorella vulgaris) for biofuel production. Clean Technologies and Environmental Policy, 2016: p. 1-11.

56. Yanfen, L., H. Zehao, and M. Xiaoqian, Energy analysis and environmental impacts of microalgal biodiesel in China. Energy Policy, 2012. 45: p. 142-151.

57. Wang, J., J.S. Wang, and Y. Yu, Microwave drying characteristics and dried quality of pumpkin. International journal of food science \& technology, 2007. 42(2): p. 148-156.

58. Clary, C., et al., Improving grape quality using microwave vacuum drying associated with temperature control. Journal of Food Science, 2007. 72(1): p. E023-E028.

59. Feng, H. and J. Tang, Microwave finish drying of diced apples in a spouted bed. Journal of Food Science, 1998. 63(4): p. 679-683.

60. Kaasova, J., et al., Physical and chemical changes during microwave drying of rice. Chemical Papers-slovak Academy of Sciences, 2002. 56(1): p. 32-35.

61. Mekhtiev, M.A. and G.I. Torgovnikov, Method of check analysis of microwave-modified wood. Wood science and technology, 2004. 38(7): p. 507-519.

62. Liu, H., X. Ma, and C. Xie, Influence of Microwave Drying on the Combustion Characteristics of Food Waste. Drying Technology, 2016(just-accepted).

63. Ciolkosz, D. and R. Wallace, A review of torrefaction for bioenergy feedstock production. Biofuels, Bioproducts and Biorefining, 2011. 5(3): p. 317-329.

64. Bridgeman, T., et al., Torrefaction of reed canary grass, wheat straw and willow to enhance solid fuel qualities and combustion properties. Fuel, 2008. 87(6): p. 844-856.

65. Bergman, P.C. and J.H. Kiel. Torrefaction for biomass upgrading. in Proc. 14th European Biomass Conference, Paris, France. 2005.

66. Paoluccio, J.A., Method and apparatus for biomass torrefaction, manufacturing a storable fuel from biomass and producing offsets for the combustion products of fossil fuels and a combustible article of manufacture. 2011, Google Patents. 
67. Acharya, B., I. Sule, and A. Dutta, A review on advances of torrefaction technologies for biomass processing. Biomass Conversion and Biorefinery, 2012. 2(4): p. 349-369.

68. Felfli, F.F., et al., Wood briquette torrefaction. Energy for Sustainable Development, 2005. 9(3): p. 19-22.

69. Arias, B., et al., Influence of torrefaction on the grindability and reactivity of woody biomass. Fuel Processing Technology, 2008. 89(2): p. 169-175.

70. Deng, J., et al., Pretreatment of agricultural residues for co-gasification via torrefaction. Journal of Analytical and Applied Pyrolysis, 2009. 86(2): p. 331-337.

71. Ren, S., et al. Microwave torrefaction of corn stover. in 2011 Louisville, Kentucky, August 710, 2011. 2011. American Society of Agricultural and Biological Engineers.

72. Tumuluru, J.S., et al. Proximate and ultimate compositional changes in corn stover during torrrefaction using thermogravimetric analyzer and microwaves. in 2012 Dallas, Texas, July 29-August 1, 2012. 2012. American Society of Agricultural and Biological Engineers.

73. Huang, Y., et al., Microwave torrefaction of rice straw and pennisetum. Bioresource technology, 2012. 123: p. 1-7.

74. Satpathy, S.K., et al., Torrefaction of wheat and barley straw after microwave heating. Fuel, 2014. 124: p. 269-278.

75. Lin, Y.-L., Effects of Microwave-Induced Torrefaction on Waste Straw Upgrading. International Journal of Chemical Engineering and Applications, 2015. 6(6): p. 401.

76. Ren, S., et al., Microwave torrefaction of Douglas fir sawdust pellets. Energy \& Fuels, 2012. 26(9): p. 5936-5943.

77. Thostenson, E. and T.-W. Chou, Microwave processing: fundamentals and applications. Composites Part A: Applied Science and Manufacturing, 1999. 30(9): p. 1055-1071.

78. Bach, Q.-V. and $\varnothing$. Skreiberg, Upgrading biomass fuels via wet torrefaction: a review and comparison with dry torrefaction. Renewable and Sustainable Energy Reviews, 2016. 54: p. 665-677.

79. Sadaka, S. and S. Negi, Improvements of biomass physical and thermochemical characteristics via torrefaction process. Environmental Progress \& Sustainable Energy, 2009. 28(3): p. 427-434.

80. Van der Stelt, M., et al., Biomass upgrading by torrefaction for the production of biofuels: $A$ review. Biomass and bioenergy, 2011. 35(9): p. 3748-3762.

81. Li, M.-F., et al., Wet torrefaction of bamboo in hydrochloric acid solution by microwave heating. ACS Sustainable Chemistry \& Engineering, 2015. 3(9): p. 2022-2029.

82. Bach, Q.-V., et al., Comparative assessment of wet torrefaction. Energy \& Fuels, 2013. 27(11): p. 6743-6753.

83. Funke, A. and F. Ziegler, Hydrothermal carbonization of biomass: a summary and discussion of chemical mechanisms for process engineering. Biofuels, Bioproducts and Biorefining, 2010. 4(2): p. 160-177.

84. Libra, J.A., et al., Hydrothermal carbonization of biomass residuals: a comparative review of the chemistry, processes and applications of wet and dry pyrolysis. Biofuels, 2011. 2(1): p. 71-106.

85. Yan, W., et al., Thermal pretreatment of lignocellulosic biomass. Environmental Progress \& Sustainable Energy, 2009. 28(3): p. 435-440.

86. Acharya, B., A. Dutta, and J. Minaret, Review on comparative study of dry and wet torrefaction. Sustainable Energy Technologies and Assessments, 2015. 12: p. 26-37.

87. Chen, W.-H., S.-C. Ye, and H.-K. Sheen, Hydrothermal carbonization of sugarcane bagasse via wet torrefaction in association with microwave heating. Bioresource technology, 2012. 118: p. 195-203.

88. Elaigwu, S.E. and G.M. Greenway, Microwave-assisted hydrothermal carbonization of rapeseed husk: A strategy for improving its solid fuel properties. Fuel Processing Technology, 2016. 149: p. 305-312. 
89. Bach, Q.-V., et al., Wet torrefaction of microalga Chlorella vulgaris ESP-31 with microwaveassisted heating. Energy Conversion and Management, 2016.

90. Kostas, E.T., et al., Selection of yeast strains for bioethanol production from UK seaweeds. Journal of applied phycology, 2016. 28(2): p. 1427-1441.

91. Yanik, J., et al., Pyrolysis of algal biomass. Journal of Analytical and Applied Pyrolysis, 2013. 103: p. 134-141.

92. Yuan, Y. and D.J. Macquarrie, Microwave Assisted Acid Hydrolysis of Brown Seaweed Ascophyllum nodosum for Bioethanol Production and Characterization of Alga Residue. ACS Sustainable Chemistry \& Engineering, 2015. 3(7): p. 1359-1365.

93. Zhang, Z., et al., Organosolv pretreatment of plant biomass for enhanced enzymatic saccharification. Green Chemistry, 2016. 18(2): p. 360-381.

94. Li, M.-F., et al., Organosolv fractionation of lignocelluloses for fuels, chemicals and materials: a biorefinery processing perspective, in Biomass Conversion. 2012, Springer. p. 341-379.

95. Liu, J., et al., Microwave-assisted pretreatment of recalcitrant softwood in aqueous glycerol. Bioresource technology, 2010. 101(23): p. 9355-9360.

96. Zheng, A., et al., Overcoming biomass recalcitrance for enhancing sugar production from fast pyrolysis of biomass by microwave pretreatment in glycerol. Green Chemistry, 2015. 17(2): p. 1167-1175.

97. Bridgwater, A.V., Review of fast pyrolysis of biomass and product upgrading. Biomass and bioenergy, 2012. 38: p. 68-94.

98. Bridgwater, A. and G. Peacocke, Fast pyrolysis processes for biomass. Renewable and sustainable energy reviews, 2000. 4(1): p. 1-73.

99. Layton, D.S., et al., Engineering ethanologenic Escherichia coli for levoglucosan utilization. Bioresource technology, 2011. 102(17): p. 8318-8322.

100. Jarboe, L.R., et al., Hybrid thermochemical processing: fermentation of pyrolysis-derived biooil. Applied microbiology and biotechnology, 2011. 91(6): p. 1519-1523.

101. Bennett, N.M., S.S. Helle, and S.J. Duff, Extraction and hydrolysis of levoglucosan from pyrolysis oil. Bioresource Technology, 2009. 100(23): p. 6059-6063.

102. Kuzhiyil, N., et al., Pyrolytic sugars from cellulosic biomass. ChemSusChem, 2012. 5(11): p. 2228-2236.

103. Zheng, A., et al., Bridging the gap between pyrolysis and fermentation: improving anhydrosugar production from fast pyrolysis of agriculture and forest residues by microwaveassisted organosolv pretreatment. ACS Sustainable Chemistry \& Engineering, 2016.

104. Karakashev, D., A.B. Thomsen, and I. Angelidaki, Anaerobic biotechnological approaches for production of liquid energy carriers from biomass. Biotechnology letters, 2007. 29(7): p. 1005-1012.

105. Gupta, A. and J.P. Verma, Sustainable bio-ethanol production from agro-residues: a review. Renewable and Sustainable Energy Reviews, 2015. 41: p. 550-567.

106. Mood, S.H., et al., Lignocellulosic biomass to bioethanol, a comprehensive review with a focus on pretreatment. Renewable and Sustainable Energy Reviews, 2013. 27: p. 77-93.

107. Kallioinen, A., et al., A novel alkaline oxidation pretreatment for spruce, birch and sugar cane bagasse. Bioresource technology, 2013. 140: p. 414-420.

108. Bothast, R. and M. Schlicher, Biotechnological processes for conversion of corn into ethanol. Applied microbiology and biotechnology, 2005. 67(1): p. 19-25.

109. Lu, X., Y. Zhang, and I. Angelidaki, Optimization of H 2 SO 4-catalyzed hydrothermal pretreatment of rapeseed straw for bioconversion to ethanol: focusing on pretreatment at high solids content. Bioresource technology, 2009. 100(12): p. 3048-3053.

110. Gomez, L.D., C.G. Steele-King, and S.J. McQueen-Mason, Sustainable liquid biofuels from biomass: the writing's on the walls. New Phytologist, 2008. 178(3): p. 473-485.

111. Dodd, D. and I.K. Cann, Enzymatic deconstruction of xylan for biofuel production. GCB Bioenergy, 2009. 1(1): p. 2-17. 
112. Pauly, M. and K. Keegstra, Cell-wall carbohydrates and their modification as a resource for biofuels. The Plant Journal, 2008. 54(4): p. 559-568.

113. Taherzadeh, M.J. and K. Karimi, Pretreatment of lignocellulosic wastes to improve ethanol and biogas production: a review. International journal of molecular sciences, 2008. 9(9): p. 1621-1651.

114. Macquarrie, D.J., J.H. Clark, and E. Fitzpatrick, The microwave pyrolysis of biomass. Biofuels, Bioproducts and Biorefining, 2012. 6(5): p. 549-560.

115. Odhner, P.B., et al., Biogas from lignocellulosic biomass. Rapport SGC, 2012. 247: p. 11027371.

116. Maurya, D.P., et al., Optimization of enzymatic saccharification of microwave pretreated sugarcane tops through response surface methodology for biofuel. 2013.

117. Ma, H., et al., Enhanced enzymatic saccharification of rice straw by microwave pretreatment. Bioresource Technology, 2009. 100(3): p. 1279-1284.

118. Intanakul, P., M. Krairiksh, and P. Kitchaiya, Enhancement of enzymatic hydrolysis of lignocellulosic wastes by microwave pretreatment under atmospheric pressure. Journal of Wood Chemistry and Technology, 2003. 23(2): p. 217-225.

119. Zhu, S., et al., Simultaneous saccharification and fermentation of microwave/alkali pretreated rice straw to ethanol. Biosystems Engineering, 2005. 92(2): p. 229-235.

120. Zhao, X., et al., Microwave pretreatment of substrates for cellulase production by solid-state fermentation. Applied biochemistry and biotechnology, 2010. 160(5): p. 1557-1571.

121. Singh, A., et al., Enhanced saccharification of rice straw and hull by microwave-alkali pretreatment and lignocellulolytic enzyme production. Bioresource technology, 2011. 102(2): p. $1773-1782$.

122. Lu, X., et al., Microwave pretreatment of rape straw for bioethanol production: focus on energy efficiency. Bioresource technology, 2011. 102(17): p. 7937-7940.

123. Chen, W.-H., Y.-J. Tu, and H.-K. Sheen, Disruption of sugarcane bagasse lignocellulosic structure by means of dilute sulfuric acid pretreatment with microwave-assisted heating. Applied Energy, 2011. 88(8): p. 2726-2734.

124. Binod, P., et al., Short duration microwave assisted pretreatment enhances the enzymatic saccharification and fermentable sugar yield from sugarcane bagasse. Renewable Energy, 2012. 37(1): p. 109-116.

125. Jackowiak, D., et al., Optimisation of a microwave pretreatment of wheat straw for methane production. Bioresource technology, 2011. 102(12): p. 6750-6756.

126. $\mathrm{Xu}, \mathrm{J}$., et al., Optimization of microwave pretreatment on wheat straw for ethanol production. biomass and bioenergy, 2011. 35(9): p. 3859-3864.

127. Thangavelu, S.K., A.S. Ahmed, and F.N. Ani, Bioethanol production from sago pith waste using microwave hydrothermal hydrolysis accelerated by carbon dioxide. Applied Energy, 2014. 128: p. 277-283.

128. Coelho, E., et al., Microwave superheated water and dilute alkali extraction of brewers'spent grain arabinoxylans and arabinoxylo-oligosaccharides. Carbohydrate polymers, 2014. 99: p. 415-422.

129. Wilkinson, S., K.A. Smart, and D.J. Cook, Optimising the (microwave) hydrothermal pretreatment of brewers spent grains for bioethanol production. Journal of Fuels, 2015. 2015.

130. Nomanbhay, S.M., R. Hussain, and K. Palanisamy, Microwave-assisted alkaline pretreatment and microwave assisted enzymatic saccharification of oil palm empty fruit bunch fiber for enhanced fermentable sugar yield. 2013.

131. Silverstein, R.A., et al., A comparison of chemical pretreatment methods for improving saccharification of cotton stalks. Bioresource Technology, 2007. 98(16): p. 3000-3011.

132. Hu, Z. and Z. Wen, Enhancing enzymatic digestibility of switchgrass by microwave-assisted alkali pretreatment. Biochemical Engineering Journal, 2008. 38(3): p. 369-378. 
133. Boonmanumsin, P., et al., Release of monomeric sugars from Miscanthus sinensis by microwave-assisted ammonia and phosphoric acid treatments. Bioresource technology, 2012. 103(1): p. 425-431.

134. Sudha, A., et al., Enhancing fermentable sugar yield from cassava pulp for bioethanol production: microwave-coupled enzymatic hydrolysis approach. Bioprocess and biosystems engineering, 2015. 38(8): p. 1509-1515.

135. Binod, P., et al., Bioethanol production from rice straw: an overview. Bioresource technology, 2010. 101(13): p. 4767-4774.

136. de Souza Moretti, M.M., et al., Pretreatment of sugarcane bagasse with microwaves irradiation and its effects on the structure and on enzymatic hydrolysis. Applied Energy, 2014. 122: p. 189-195.

137. Diaz, A.B., et al., Evaluation of microwave-assisted pretreatment of lignocellulosic biomass immersed in alkaline glycerol for fermentable sugars production. Bioresource technology, 2015. 185: p. 316-323.

138. Rani, R.U., et al., Low temperature thermo-chemical pretreatment of dairy waste activated sludge for anaerobic digestion process. Bioresource technology, 2012. 103(1): p. 415-424.

139. Kelleher, B., et al., Advances in poultry litter disposal technology-a review. Bioresource technology, 2002. 83(1): p. 27-36.

140. Chen, Y., J.J. Cheng, and K.S. Creamer, Inhibition of anaerobic digestion process: a review. Bioresource technology, 2008. 99(10): p. 4044-4064.

141. Vavilin, V., et al., Hydrolysis kinetics in anaerobic degradation of particulate organic material: an overview. Waste management, 2008. 28(6): p. 939-951.

142. Lagerkvist, A. and F. Morgan-Sagastume, The effects of substrate pre-treatment on anaerobic digestion systems: a review. Waste Management, 2012. 32(9): p. 1634-1650.

143. Pavlostathis, S. and E. Giraldo-Gomez, Kinetics of anaerobic treatment: a critical review. Critical Reviews in Environmental Science and Technology, 1991. 21(5-6): p. 411-490.

144. Penaud, V., J. Delgenes, and R. Moletta, Thermo-chemical pretreatment of a microbial biomass: influence of sodium hydroxide addition on solubilization and anaerobic biodegradability. Enzyme and microbial technology, 1999. 25(3): p. 258-263.

145. Pavlostathis, S.G. and J.M. Gossett, A kinetic model for anaerobic digestion of biological sludge. Biotechnology and bioengineering, 1986. 28(10): p. 1519-1530.

146. Feki, E., et al., Improvement of anaerobic digestion of waste-activated sludge by using $\mathrm{H} 2 \mathrm{O} 2$ oxidation, electrolysis, electro-oxidation and thermo-alkaline pretreatments. Environmental Science and Pollution Research, 2015. 22(19): p. 14717-14726.

147. Kavitha, S., et al., The enhancement of anaerobic biodegradability of waste activated sludge by surfactant mediated biological pretreatment. Bioresource technology, 2014. 168: p. 159166.

148. Martín, M.Á., et al., Evaluation of the improvement of sonication pre-treatment in the anaerobic digestion of sewage sludge. Journal of environmental management, 2015. 147: p. 330-337.

149. Eskicioglu, C., R.L. Droste, and K.J. Kennedy, Performance of anaerobic waste activated sludge digesters after microwave pretreatment. Water Environment Research, 2007. 79(11): p. 2265-2273.

150. Eskicioglu, C., K.J. Kennedy, and R.L. Droste, Enhancement of batch waste activated sludge digestion by microwave pretreatment. Water Environment Research, 2007. 79(11): p. 23042317.

151. Toreci, I., K.J. Kennedy, and R.L. Droste, Effect of high-temperature microwave irradiation on municipal thickened waste activated sludge solubilization. Heat Transfer Engineering, 2010. 31(9): p. 766-773.

152. Park, B., et al., Use of microwave pretreatment for enhanced anaerobiosis of secondary sludge. Water Science and Technology, 2004. 50(9): p. 17-23. 
153. Appels, L., et al., Influence of microwave pre-treatment on sludge solubilization and pilot scale semi-continuous anaerobic digestion. Bioresource technology, 2013. 128: p. 598-603.

154. Wojciechowska, E., Application of microwaves for sewage sludge conditioning. Water research, 2005. 39(19): p. 4749-4754.

155. Hong, S.M., J.K. Park, and Y. Lee, Mechanisms of microwave irradiation involved in the destruction of fecal coliforms from biosolids. Water Research, 2004. 38(6): p. 1615-1625.

156. Eskicioglu, C., et al., Synergetic pretreatment of sewage sludge by microwave irradiation in presence of H 2 O 2 for enhanced anaerobic digestion. Water Research, 2008. 42(18): p. 4674-4682.

157. Ebenezer, A.V., et al., Influence of deflocculation on microwave disintegration and anaerobic biodegradability of waste activated sludge. Bioresource technology, 2015. 185: p. 194-201.

158. Liu, J., et al., Microwave and its combined processes: an effective way for enhancing anaerobic digestion and dewaterability of sewage sludge? Journal of Water Reuse and Desalination, 2015. 5(3): p. 264-270.

159. Chi, Y., et al., Enhancement of thermophilic anaerobic digestion of thickened waste activated sludge by combined microwave and alkaline pretreatment. Journal of environmental Sciences, 2011. 23(8): p. 1257-1265.

160. Jang, J.-H. and J.-H. Ahn, Effect of microwave pretreatment in presence of $\mathrm{NaOH}$ on mesophilic anaerobic digestion of thickened waste activated sludge. Bioresource technology, 2013. 131: p. 437-442.

161. Doğan, I. and F.D. Sanin, Alkaline solubilization and microwave irradiation as a combined sludge disintegration and minimization method. Water Research, 2009. 43(8): p. 2139-2148.

162. Xiao, Q., et al., Optimization of $\mathrm{H} 2 \mathrm{O} 2$ dosage in microwave-H $2 \mathrm{O} 2$ process for sludge pretreatment with uniform design method. Journal of Environmental Sciences, 2012. 24(12): p. 2060-2067.

163. Oncu, N.B. and I.A. Balcioglu, Microwave-assisted chemical oxidation of biological waste sludge: simultaneous micropollutant degradation and sludge solubilization. Bioresource technology, 2013. 146: p. 126-134.

164. Chang, C.-J., V.K. Tyagi, and S.-L. Lo, Effects of microwave and alkali induced pretreatment on sludge solubilization and subsequent aerobic digestion. Bioresource Technology, 2011. 102(17): p. 7633-7640.

165. Tyagi, V.K. and S.-L. Lo, Enhancement in mesophilic aerobic digestion of waste activated sludge by chemically assisted thermal pretreatment method. Bioresource technology, 2012. 119: p. 105-113.

166. Tyagi, V.K. and S.-L. Lo, Microwave irradiation: A sustainable way for sludge treatment and resource recovery. Renewable and Sustainable Energy Reviews, 2013. 18: p. 288-305.

167. Liu, J., et al., Rheological properties of sewage sludge during enhanced anaerobic digestion with microwave-H 2 O 2 pretreatment. Water research, 2016. 98: p. 98-108.

168. Ratkovich, N., et al., Activated sludge rheology: a critical review on data collection and modelling. Water research, 2013. 47(2): p. 463-482.

169. Eswari, P., et al., Enhancement of sludge anaerobic biodegradability by combined microwave-H2O2 pretreatment in acidic conditions. Environmental Science and Pollution Research, 2016: p. 1-13.

170. Rawat, I., et al., Biodiesel from microalgae: a critical evaluation from laboratory to large scale production. Applied Energy, 2013. 103: p. 444-467.

171. Passos, F. and I. Ferrer, Influence of hydrothermal pretreatment on microalgal biomass anaerobic digestion and bioenergy production. Water research, 2015. 68: p. 364-373.

172. Passos, F., J. Carretero, and I. Ferrer, Comparing pretreatment methods for improving microalgae anaerobic digestion: thermal, hydrothermal, microwave and ultrasound. Chemical Engineering Journal, 2015. 279: p. 667-672. 
173. Passos, F., et al., Biogas production from microalgae grown in wastewater: effect of microwave pretreatment. Applied energy, 2013. 108: p. 168-175.

174. Passos, F., et al., Long-term anaerobic digestion of microalgae grown in HRAP for wastewater treatment. Effect of microwave pretreatment. Water research, 2014. 49: p. 351359.

175. Beneroso, D., et al., Microwave pyrolysis of biomass for bio-oil production: Scalable processing concepts. Chemical Engineering Journal, 2017. 316: p. 481-498.

176. Robinson, J., et al., Microwave pyrolysis of biomass: control of process parameters for high pyrolysis oil yields and enhanced oil quality. Energy \& Fuels, 2015. 29(3): p. 1701-1709.

177. Meredith, R.J., Engineers' handbook of industrial microwave heating. 1998: IET.

178. Fennell, L.P. and D. Boldor, Dielectric and thermal properties of sweet sorghum biomass. Journal of Microwave Power and Electromagnetic Energy, 2014. 48(4): p. 244-260.

179. Jie, W.S., et al., Dielectric Properties of Oil Palm Trunk Core. Journal of Clean Energy Technologies, 2015. 3(6).

180. Salema, A.A., et al., Dielectric properties and microwave heating of oil palm biomass and biochar. Industrial Crops and Products, 2013. 50: p. 366-374.

181. Tripathi, M., et al., Effect of microwave frequency on dielectric properties of oil palm shell (OPS) and OPS char synthesized by microwave pyrolysis of OPS. Journal of Analytical and Applied Pyrolysis, 2015. 112: p. 306-312.

182. Ramasamy, S. and B. Moghtaderi, Dielectric properties of typical Australian wood-based biomass materials at microwave frequency. Energy \& Fuels, 2010. 24(8): p. 4534-4548.

183. Robinson, J., et al., Microwave pyrolysis of wood pellets. Industrial \& Engineering Chemistry Research, 2009. 49(2): p. 459-463.

184. Zi, W.H., et al. Study on the Dielectric Properties of Biomass Material of Tobacco Stems. in Advanced Materials Research. 2013. Trans Tech Publ.

185. Motasemi, F., M.T. Afzal, and A.A. Salema, Microwave dielectric characterization of hay during pyrolysis. Industrial Crops and Products, 2014. 61: p. 492-498.

186. Motasemi, F., et al., Microwave dielectric characterization of switchgrass for bioenergy and biofuel. Fuel, 2014. 124: p. 151-157.

187. Motasemi, F., A.A. Salema, and M.T. Afzal, Dielectric characterization of corn stover for microwave processing technology. Fuel Processing Technology, 2015. 131: p. 370-375.

188. Beneroso, D., et al., Dielectric characterization of biodegradable wastes during pyrolysis. Fuel, 2016. 172: p. 146-152.

189. Motasemi, F., A.A. Salema, and M.T. Afzal, Microwave Dielectric Properties of Agricultural Biomass at High Temperature in an Inert Environment. Transactions of the ASABE, 2015. 58(3): p. 869-877.

190. Robinson, J., et al., Understanding microwave heating effects in single mode type cavitiestheory and experiment. Physical Chemistry Chemical Physics, 2010. 12(18): p. 4750-4758.

191. Huang, Y.-F., P.-T. Chiueh, and S.-L. Lo, A review on microwave pyrolysis of lignocellulosic biomass. Sustainable Environment Research, 2016.

192. Budarin, V.L., et al., Microwave assisted decomposition of cellulose: A new thermochemical route for biomass exploitation. Bioresource Technology, 2010. 101(10): p. 3776-3779.

193. Fan, J., et al., Direct microwave-assisted hydrothermal depolymerization of cellulose. Journal of the American Chemical Society, 2013. 135(32): p. 11728-11731.

194. Fan, J., et al., Microwave-enhanced formation of glucose from cellulosic waste. Chemical Engineering and Processing: Process Intensification, 2013. 71: p. 37-42.

195. Salema, A.A. and F.N. Ani, Microwave-assisted pyrolysis of oil palm shell biomass using an overhead stirrer. Journal of Analytical and Applied Pyrolysis, 2012. 96: p. 162-172.

196. Berger, D. and D. Pei, Drying of hygroscopic capillary porous solids-a theoretical approach. International Journal of Heat and Mass Transfer, 1973. 16(2): p. 293-302. 
197. Stanish, M., G. Schajer, and F. Kayihan, A mathematical model of drying for hygroscopic porous media. AIChE Journal, 1986. 32(8): p. 1301-1311.

198. Lanigan, B., Microwave processing of lignocellulosic biomass for production of fuels. 2010.

199. Bioenergy, I., Bioenergy-a sustainable and reliable energy source. International Energy Agency Bioenergy, Paris, France, 2009.

200. Wang, M., et al., Microwave-induced torrefaction of rice husk and sugarcane residues. Energy, 2012. 37(1): p. 177-184.

201. Liao, P.H., et al., Sludge reduction and volatile fatty acid recovery using microwave advanced oxidation process. Journal of Environmental Science and Health Part A, 2007. 42(5): p. 633639.

202. Chan, W.I., et al., Sewage sludge nutrient solubilization using a single-stage microwave treatment. Journal of Environmental Science and Health Part A, 2007. 42(1): p. 59-63.

203. Kenge, A.A., P.H. Liao, and K.V. Lo, Role of mixing on microwave-enhanced advanced oxidation process in treating sewage sludge. Journal of Environmental Science and Health Part A, 2008. 43(12): p. 1431-1440.

204. Kenge, A.A., P.H. Liao, and K.V. Lo, Treating solid dairy manure using microwave-enhanced advanced oxidation process. Journal of Environmental Science and Health, Part B, 2009. 44(6): p. 606-612.

205. Lo, K.V., P.H. Liao, and G.Q. Yin, Sewage sludge treatment using microwave-enhanced advanced oxidation processes with and without ferrous sulfate addition. Journal of chemical technology and biotechnology, 2008. 83(10): p. 1370-1374.

206. Wang, Y., Y. Wei, and J. Liu, Effect of $\mathrm{H} 2 \mathrm{O} 2$ dosing strategy on sludge pretreatment by microwave-H 2 O 2 advanced oxidation process. Journal of Hazardous Materials, 2009. 169(1): p. 680-684.

207. Yin, G.Q., P.H. Liao, and K.V. Lo, Sewage sludge treatment using microwave-enhanced advanced oxidation process. Journal of Environmental Science and Health Part A, 2008. 43(2): p. 191-201.

208. Yu, Y., et al., Disinfection and solubilization of sewage sludge using the microwave enhanced advanced oxidation process. Journal of hazardous materials, 2010. 181(1): p. 1143-1147.

209. Liu, J., et al., Does residual $\mathrm{H} 2 \mathrm{O} 2$ result in inhibitory effect on enhanced anaerobic digestion of sludge pretreated by microwave-H2O2 pretreatment process? Environmental Science and Pollution Research, 2015: p. 1-10. 


\section{FIGURE CAPTIONS}

Figure 1. Overview of current bioenergy routes which can be applied to different biomass feedstocks and the potential products of energy that can be produced (Adapted from [199])

Figure 2. The differences in temperature distribution and direction of heat transfer between conventional and microwave heating.

A) Conventional heating: heat is transferred from the outside of the material inwards by conduction. Overheating can occur on the outside whist still maintaining a cooler inner region. B) Microwave heating: MWs penetrate the material and heat volumetrically. Energy is then uniformly dissipated throughout the material.

Figure 3. Overview of MW-assisted organosolv pre-treatment of biomass followed by fast pyrolysis for the production of levoglucosan. Levoglucosan can then be acid hydrolysed to glucose and subsequently fermented to bioethanol by fermentative microorganisms.

Figure 4. Schematic overview of the lignocellulosic structure.

Figure 5. Industrial conversion of lignocellulosic feedstocks to fermentable sugars which can then be fermented to bioethanol: key processes

Figure 6. Overview of anaerobic digestion process.

Figure 7. Schematic representation illustrating the possible effects of a hot spot inside a single mode cavity on pre-treatment severity of biomass.

Figure 8. Electromagnetic simulation depicting the electric field distribution in a single mode cavity with a quartz tube containing n-heptane. Image on the left contains no stirrer or fibre optic probe. Image on right contains stirrer and fibre optic probe. 


\section{Figure 1.}

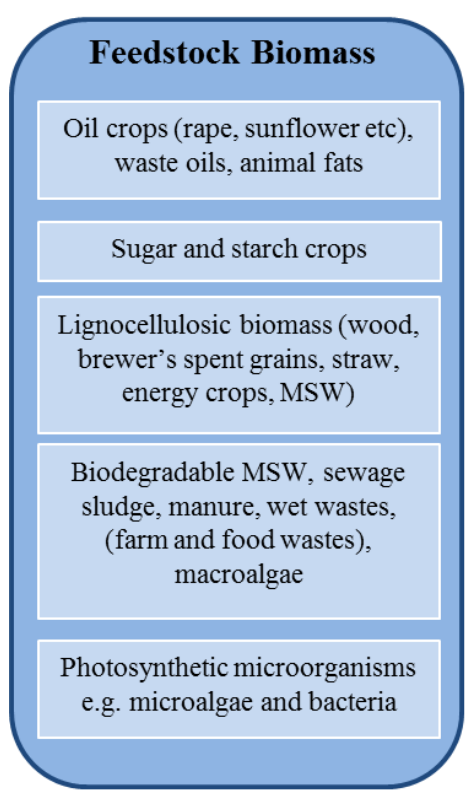

3

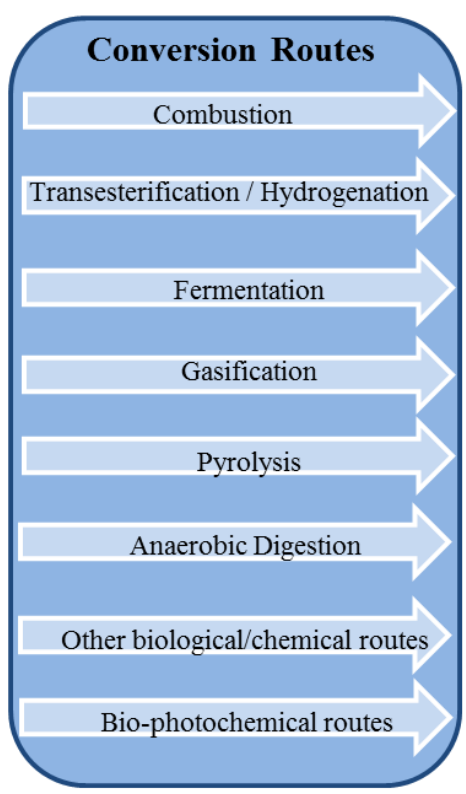

4

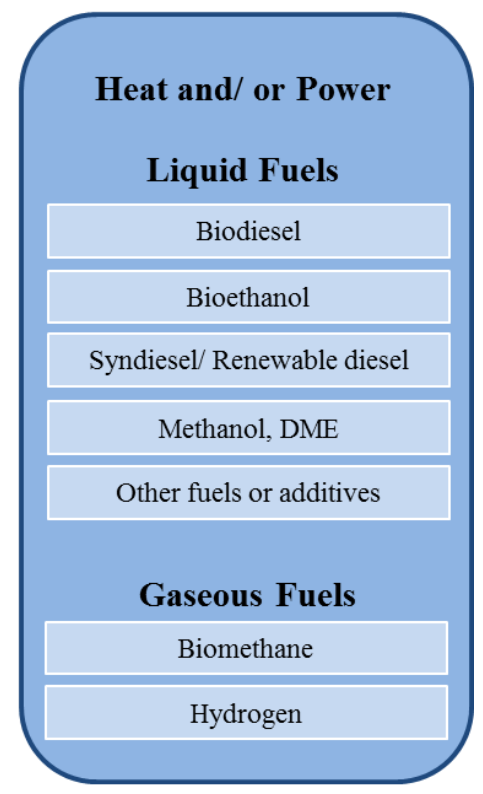


Figure 2.

A

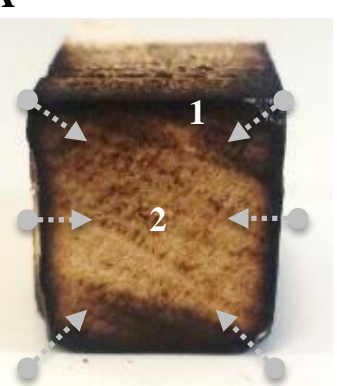

$1=$ hotter region $2=$ cooler region

B

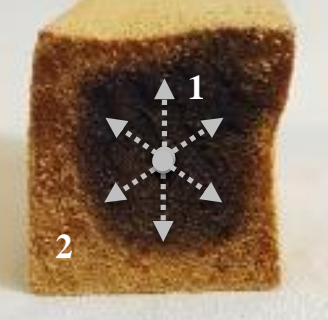

cooler region 
Figure 3.

Biomass

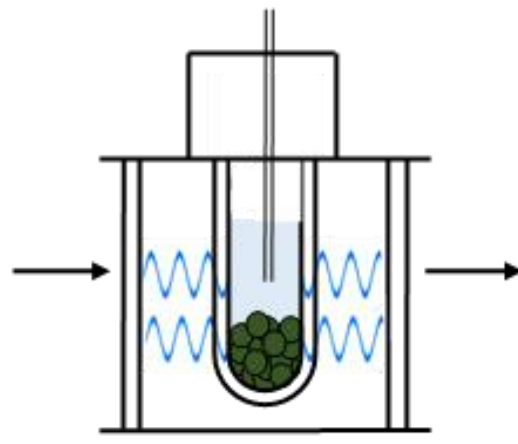

Microwave

Organosolv

Pre-treatment

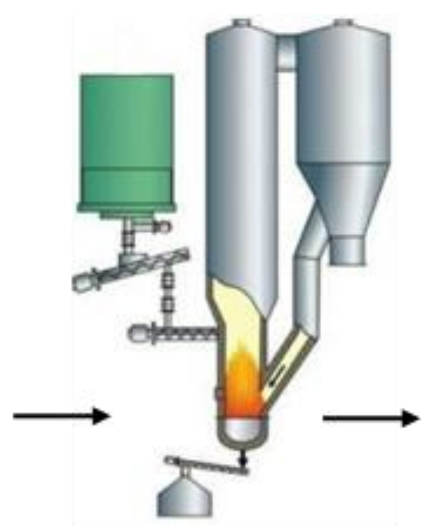

Pre-treated Residue

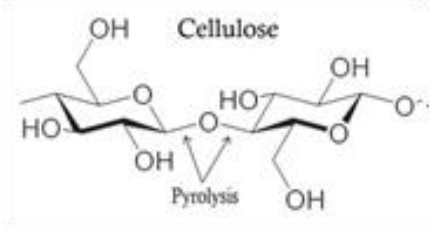

Fast Pyrolysis

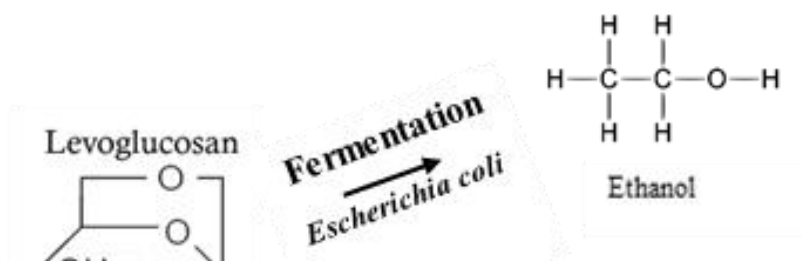

OH
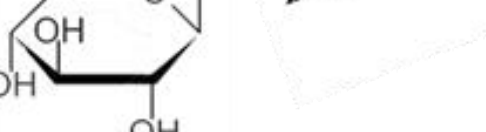
Fermentation
Saccharomyces
$\underset{\text { cerevisiae }}{\longrightarrow}$

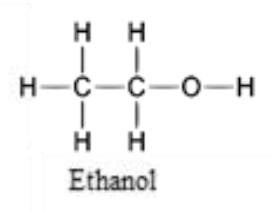


Figure 4.

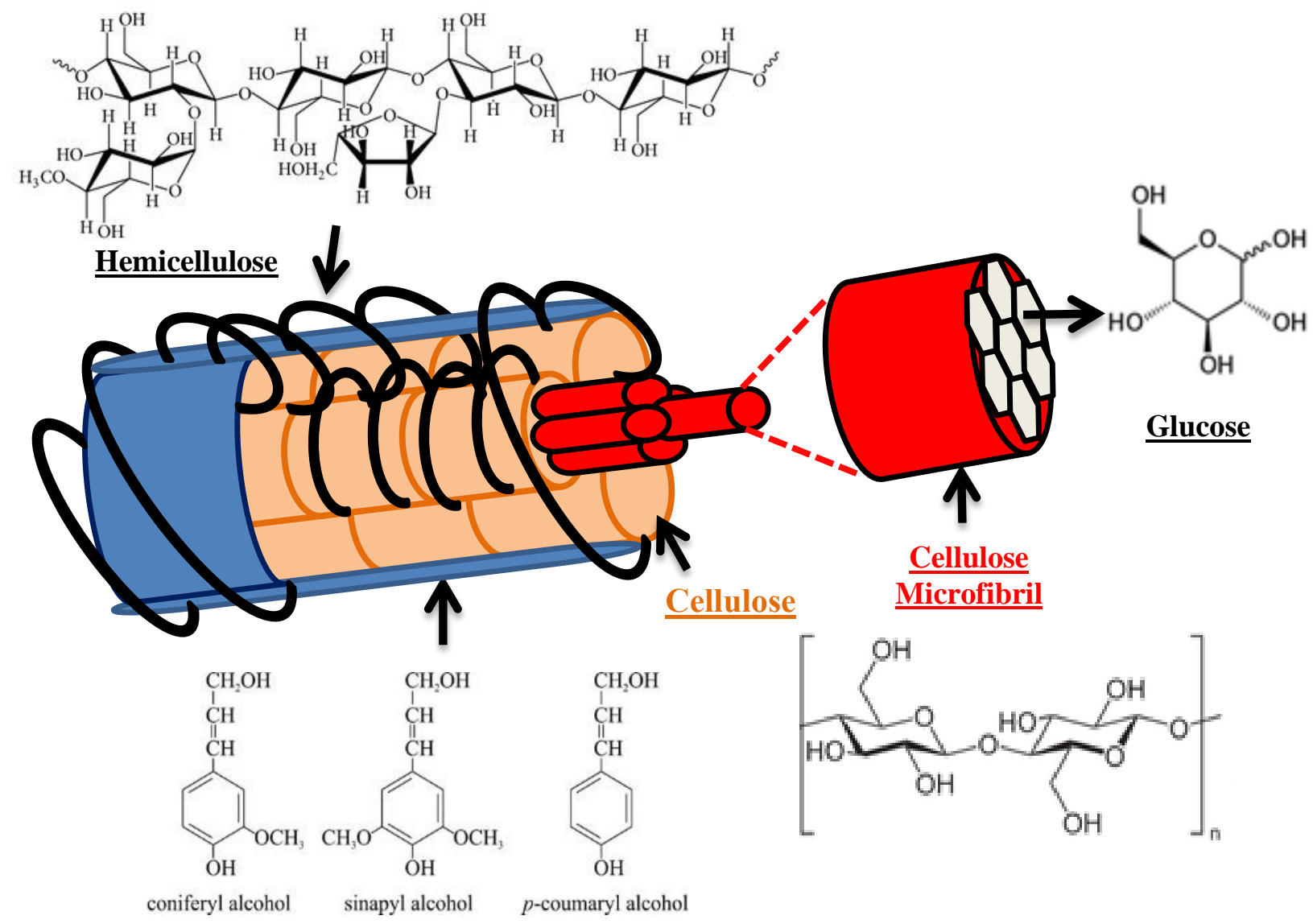

$\underline{\text { Lignin }}$ 
Figure 5.

Lignocellulosic

Feedstock

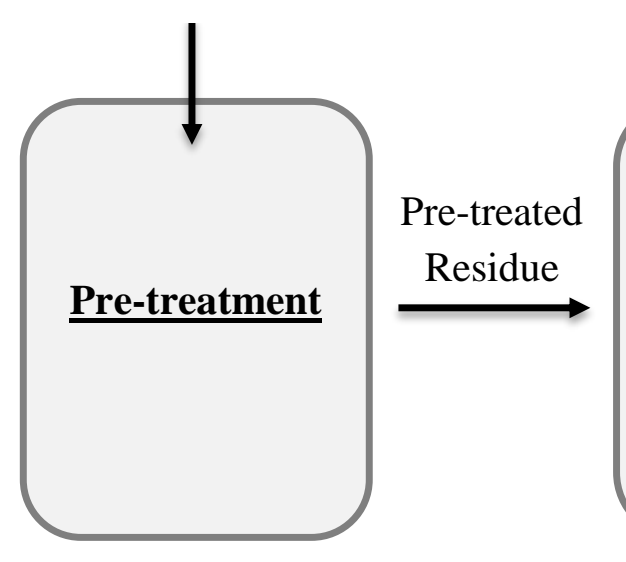

Enzymes

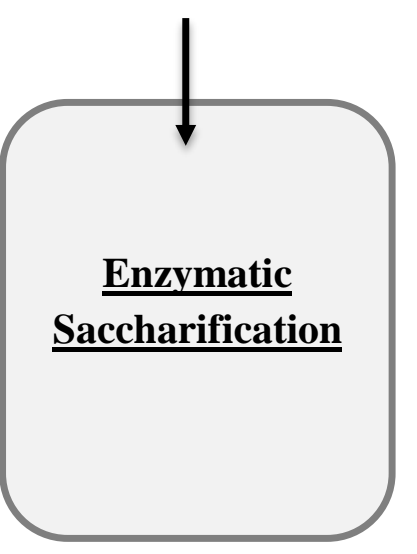

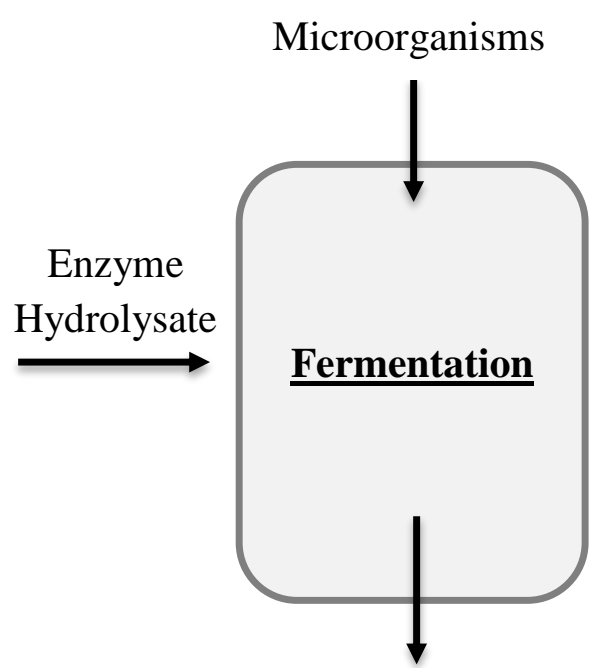

Bioethanol 


\section{Figure 6.}

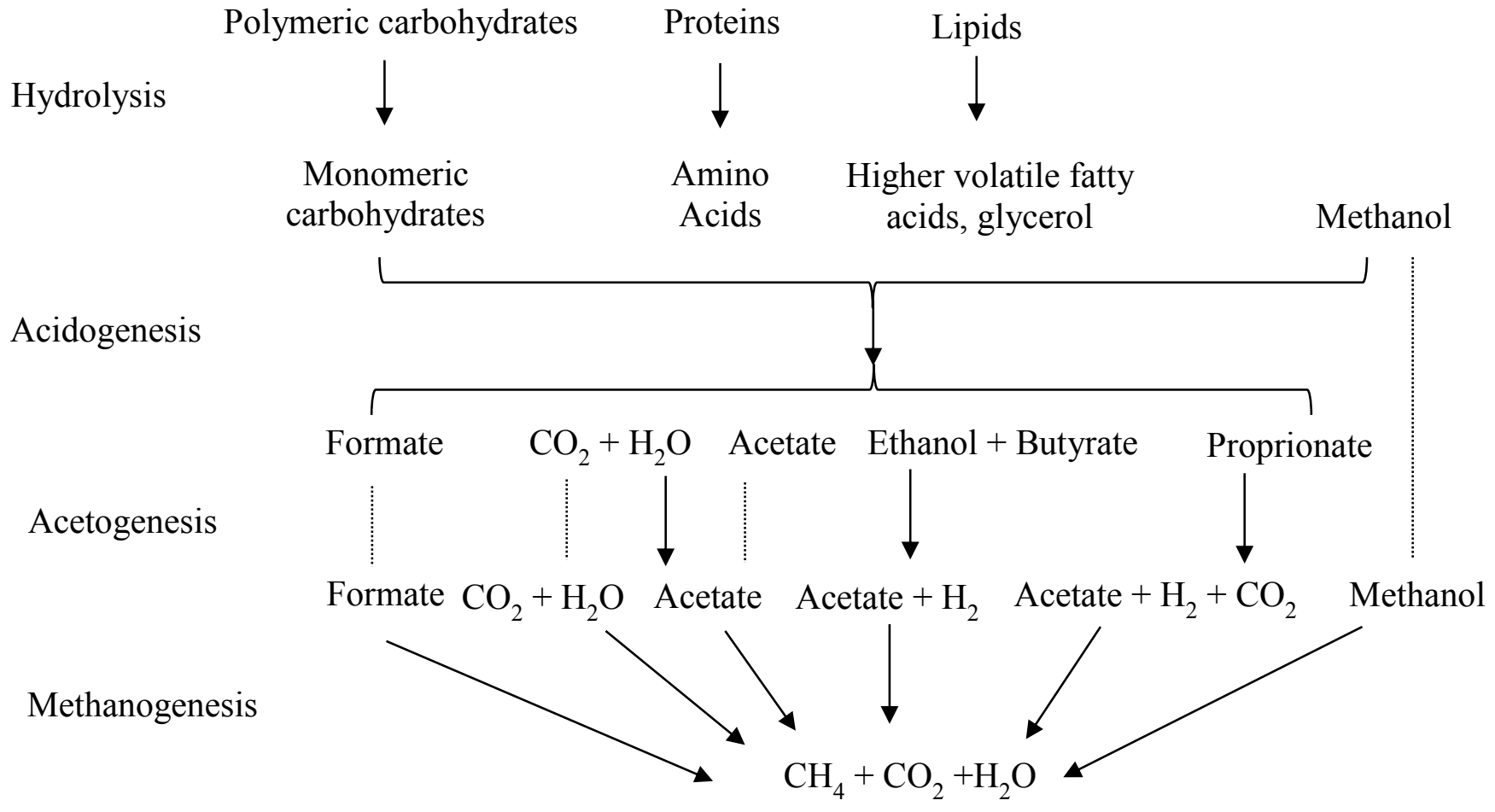


Figure 7.
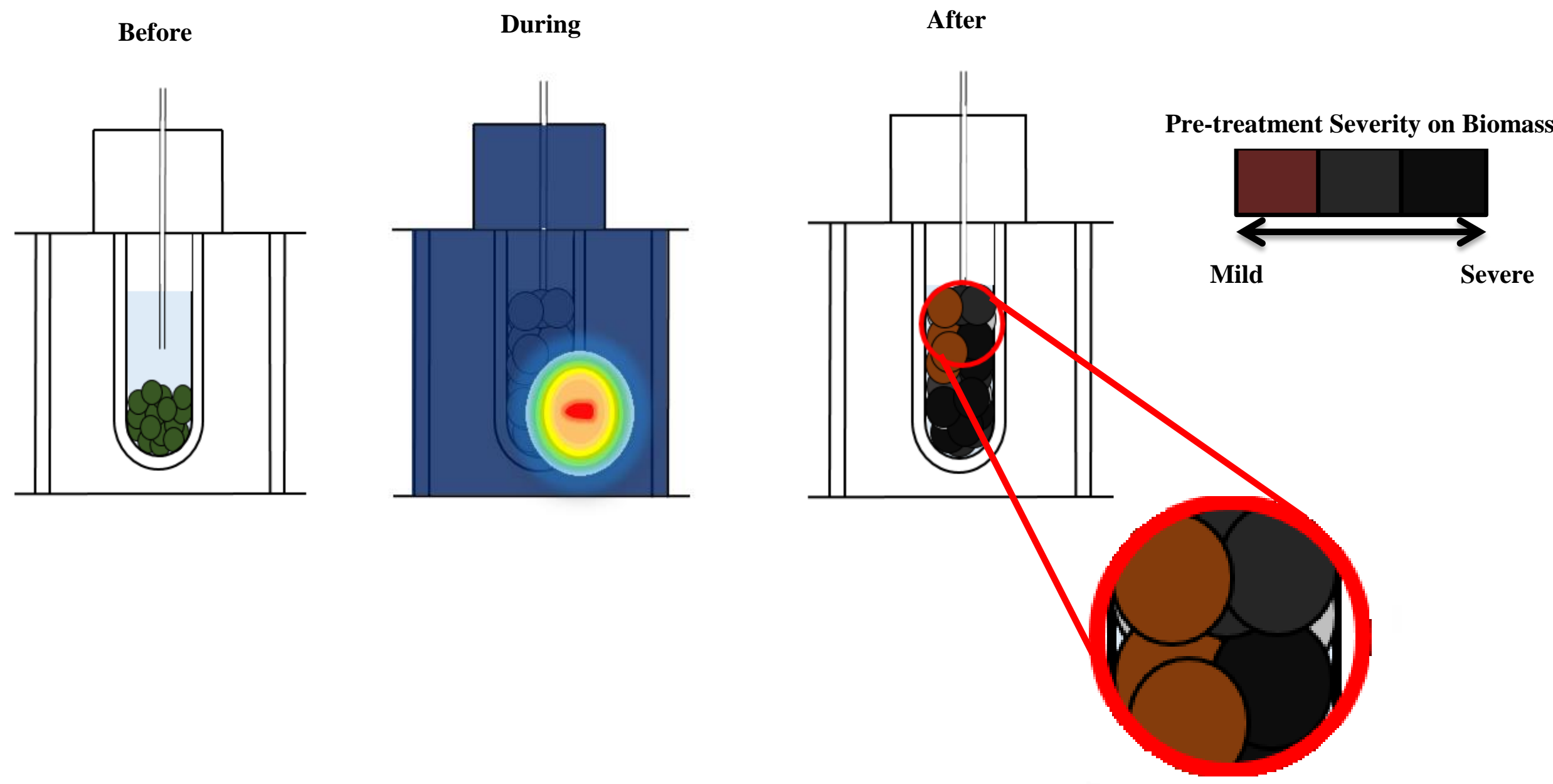
2

3

4

5

6
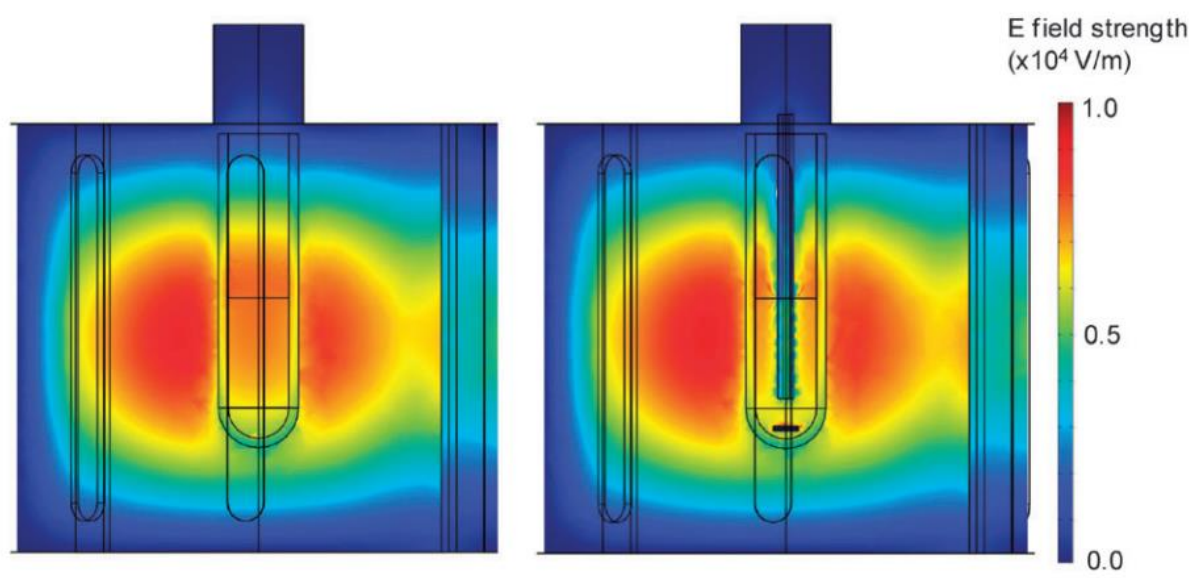

7

8

9

10

11

\section{TABLE CAPTIONS}

15 Table 1. Summary of available literature on the dry MW-torrefaction of biomass.

16 Table 2. Summary of literature on the use of MW-AOP pre-treatment for AD.

17 Table 3. Summary of the opportunities and biomass pre-treatment/upgrading solutions 18 offered by microwave heating 
25

26

27

28

29

30

31

32

33

34

35 
Table 1.

\begin{tabular}{|c|c|c|c|}
\hline Feedstock & Reaction Conditions & Findings & Reference \\
\hline Rice straw, pennisetum & $150 \mathrm{~W}, 10 \mathrm{~min}$ & $\begin{array}{l}70 \% \text { mass yield and } 80 \% \text { energy yield achieved for torrified biomass. } \\
\text { Energy density of the biomass was ca } 14 \% \text { higher than raw biomass }\end{array}$ & [73] \\
\hline Wheat straw & $300 \mathrm{~W} .20 \mathrm{~min}$ & $\begin{array}{l}72 \% \text { mass yield, } 89 \% \text { energy yield, } 23 \% \text { increase in } \mathrm{HHV} \text {. } * \text { Particle size } \\
\text { reduction ratio of } 0.66 . * \text { Moisture uptake reduction by } 61 \%\end{array}$ & [74] \\
\hline Barley straw & $250 \mathrm{~W}, 20 \mathrm{~min}$ & $\begin{array}{l}76 \% \text { mass yield, } 87 \% \text { energy yield, } 14 \% \text { increase in HHV. *Particle size } \\
\text { reduction ratio of } 0.61 . * * \text { Moisture uptake reduction by } 63 \%\end{array}$ & [74] \\
\hline Rice husk & $300 \mathrm{~W}, 4 \mathrm{~min}$ & $49.5 \%$ mass yield, $57.5 \%$ energy yield, $26 \%$ increase in calorific value & [200] \\
\hline Sugar cane residue & $250 \mathrm{~W}, 4 \mathrm{~min}$ & $67.2 \%$ mass yield, $79.4 \%$ energy yield, $57 \%$ increase in calorific value & [200] \\
\hline Douglas fir sawdust pellets & $600 \mathrm{~W}, 10 \mathrm{~min}$ & $83.2 \%$ mass yield, $90.6 \%$ energy yield, $30 \%$ improvement in HHV & [76] \\
\hline Waste straw & $350 \mathrm{~W}, 30 \mathrm{~min}$ & $68 \%$ mass yield, $88 \%$ energy yield & [75] \\
\hline
\end{tabular}

37 *Particle size reduction ratio signifies the grindability of the biomass (difference between torrified and native (non-torrified) biomass).

**Moisture uptake reduction is indicative of hydrophobicity of torrified biomass 


\begin{tabular}{|c|c|c|c|}
\hline Treatment parameters & Feedstock & Main results & Reference \\
\hline $\begin{array}{l}\mathrm{MW}\left(20^{\circ} \mathrm{C} / \mathrm{min}\right) \text { for } 5 \mathrm{~min} \text { and } \\
71 \mathrm{~mL} / \mathrm{L} \mathrm{H}_{2} \mathrm{O}_{2} \text { dosage }(30 \% \text { by } \\
\text { wt) }\end{array}$ & Sludge & $\begin{array}{l}>96 \% \text { TCOD of dissolved into } \\
\text { solution }\end{array}$ & {$[201]$} \\
\hline $\begin{array}{l}\mathrm{MW}\left(80^{\circ} \mathrm{C}\right) \text { for } 5 \mathrm{~min} \text { and } 34 \\
\mathrm{~mL} / \mathrm{L} \mathrm{H}_{2} \mathrm{O}_{2}+17 \mathrm{~mL} / \mathrm{L} \mathrm{H}_{2} \mathrm{SO}_{4}\end{array}$ & Sludge & All COD was solubilised & [202] \\
\hline $\begin{array}{l}\mathrm{MW}\left(80^{\circ} \mathrm{C}\right), 5 \text { min heating } \\
\text { time, with } 1 \mathrm{~mL} \mathrm{H}_{2} \mathrm{O}_{2}(30 \%) / 1 \\
\% \mathrm{TS} \text { dosage }\end{array}$ & WAS & $25 \%$ increase in SCOD & [203] \\
\hline $\begin{array}{l}\mathrm{MW}\left(120^{\circ} \mathrm{C}\right) \text { with } 0.80 \mathrm{~g} \\
\mathrm{H}_{2} \mathrm{O}_{2} / \mathrm{g} \text { dry sludge }\end{array}$ & WAS & $\begin{array}{l}\text { Optimum parameters for maximum } \\
\text { solids' disintegration and nutrient } \\
\text { release }\end{array}$ & [204] \\
\hline $\begin{array}{l}\mathrm{MW}\left(80^{\circ} \mathrm{C}\right) \text { for } 3 \text { min with } 1 \% \\
\mathrm{H}_{2} \mathrm{O}_{2}\end{array}$ & WAS & $18 \%$ increase in COD solubilisation & [205] \\
\hline $\begin{array}{l}\mathrm{MW}\left(120^{\circ} \mathrm{C}\right) \text { for } 10 \text { min with } 1 \\
\mathrm{~g} \mathrm{H}_{2} \mathrm{O}_{2}(30 \% \mathrm{v} / \mathrm{v} / \mathrm{g} \mathrm{TS})\end{array}$ & WAS & $\begin{array}{l}\text { COD solubilisation increase from } 3 \% \\
\text { (control) to } 24 \% \text { after pre-treatment. } \\
\text { However, no significant effect of } \\
\text { combined pre-treatment was } \\
\text { observed on methane production and } \\
\text { sludge dewaterability }\end{array}$ & {$[156]$} \\
\hline $\begin{array}{l}\text { MW heating }\left(80^{\circ} \mathrm{C}\right) \text { followed } \\
\text { by addition of } \mathrm{H}_{2} \mathrm{O}_{2} \text { and then } \\
\text { continuous heating to } 100^{\circ} \mathrm{C}\end{array}$ & WAS & $\begin{array}{l}\text { The higher the dosing rate of } \mathrm{H}_{2} \mathrm{O}_{2} \\
\text { the more SCOD was released into the } \\
\text { supernatant }\end{array}$ & [206] \\
\hline $\begin{array}{l}\mathrm{MW}\left(80^{\circ} \mathrm{C}\right) \text { for } 3 \text { min with } 2 \% \\
\mathrm{H}_{2} \mathrm{O}_{2}(0.5 \% \text { TS })\end{array}$ & WAS & $\begin{array}{l}\text { SCOD reached as high as } 87 \% \text { of } \\
\text { TCOD }\end{array}$ & [207] \\
\hline $\begin{array}{l}\mathrm{MW}\left(70^{\circ} \mathrm{C}\right) \text { with } 0.1 \% \quad \mathrm{H}_{2} \mathrm{O}_{2}(1 \\
\% \mathrm{TS})\end{array}$ & WAS & $\begin{array}{l}\text { SCOD reached } 25 \% \text { of the initial } \\
\text { TCOD }\end{array}$ & [208] \\
\hline $\begin{array}{l}\mathrm{MW}\left(100^{\circ} \mathrm{C}\right) \text { with } 0.2 \mathrm{~g} \mathrm{H}_{2} \mathrm{O}_{2} / \mathrm{g} \\
\text { TS }\end{array}$ & WAS & $\begin{array}{l}\text { Methane production improved by } \\
13.34 \%\end{array}$ & [209] \\
\hline $\begin{array}{l}\text { Combined pre-treatment of MW } \\
(18,600 \mathrm{~kJ} / \mathrm{kg} \mathrm{TS})+\mathrm{H}_{2} \mathrm{O}_{2}(0.3 \\
\mathrm{mg} / \mathrm{g} \mathrm{SS})+ \text { acid }(\mathrm{pH} 5)\end{array}$ & $\begin{array}{l}\text { Dairy } \\
\text { sludge }\end{array}$ & $\begin{array}{l}\text { Maximum methane production of } \\
232 \mathrm{~mL} / \mathrm{g} \text { VS. Cost analysis revealed } \\
\text { these parameters to be most } \\
\text { economical with a net profit of } \\
59.90 € / \text { tonne of sludge }\end{array}$ & [169] \\
\hline $\begin{array}{l}\mathrm{MW}\left(80^{\circ} \mathrm{C}\right) \text { with } 0.2 \mathrm{~g} \mathrm{H}_{2} \mathrm{O}_{2}(30 \\
\% \mathrm{w} / \mathrm{w}) / \mathrm{g} \text { TS }(8 \%) \text { then heated } \\
\text { to } 100^{\circ} \mathrm{C}\end{array}$ & WAS & $\begin{array}{l}\text { Sludge flow-ability improved after } \\
\text { the applied pre-treatment and the } \\
\text { elastic properties weakened. Changes } \\
\text { to the micro-structures (concentration } \\
\text { and components of EPS) may have } \\
\text { contributed to improvement in sludge } \\
\text { bio-digestibility }\end{array}$ & {$[167]$} \\
\hline
\end{tabular}




\section{Key biomass pre-treatment and/or upgrading features \\ Little or no biomass size reduction}

Elimination of a biomass pre-drying step

Production of highly digestible feedstocks

Reduction in the formation of inhibitory compounds

Lower energy demands and moderate costs

Feasibility and effectiveness with high solids loadings

Production of a different range and grade of compounds

Decrease in equipment size and increase in portability

\section{Process solutions and opportunities with the use of MW heating}

The fast, selective and volumetric-based heating offered by MWs enables the treatment (processing) and utilisation of non-homogeneous and large particle size biomass and also eliminates any prior biomass grinding requirements

Polar water molecules absorb microwave energy more readily than other components that may be present within the biomass. Therefore, the presence of inherent water within biomass is beneficial, as water contained within the biomass is selectively targeted and instantaneous heating of biomass is induced. The heating rate at the initial MW heating stages is also improved thus eliminating a necessary drying pre-requisite step (in order to achieve a suitable biomass moisture content)

The selective heating offered by MWs heats the more polar components of the biomass, ultimately inducing swelling and fragmentation of the material. The lignocellulosic matrix becomes modified (lignin and hemicellulose components altered or removed) and the crystallinity of cellulose decreases. Such alternations increase the surface area and increase digestibility of the biomass which render the biomass compatible with subsequent downstream process (such as enzymatic saccharification steps etc.)

The application of MWs enables greater control of the biomass heating process and enhanced chemical reactivity which essentially reduces the formation of undesired compounds that may induce inhibitory effects to microorganisms and/or enzymes in subsequent downstream processes

Higher power densities, higher heating efficiency and the ability to reach high temperatures at faster heating rates

The volumetric heating nature of the electromagnetic field offers uniform heat distribution and excellent transfer of heat across bulk volumes of biomass. This enables the processing of more biomass (mass) per unit time (increased solids loadings per reaction)

Possible due to the unique thermal gradients which result from MW heating

Reduces overall capital cost and enables mobile processing systems to treat biomass at, or close to 
source, thus reducing transport costs. 